\title{
Occupations and Work Characteristics: Effects on Retirement Expectations and Timing
}

Brooke Helppie McFall, Amanda Sonnega,

Robert J. Willis, and Peter Hudomiet

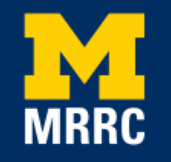

Project \#: R-UM15-01 


\title{
Occupations and Work Characteristics: Effects on Retirement Expectations and Timing
}

\author{
Brooke Helppie McFall \\ University of Michigan
}

Amanda Sonnega
University of Michigan

Robert J. Willis

University of Michigan

Peter Hudomiet

Rand Corporation

October 2015

\author{
Michigan Retirement Research Center \\ University of Michigan \\ P.O. Box 1248 \\ Ann Arbor, MI 48104 \\ www.mrrc.isr.umich.edu \\ (734) 615-0422
}

\section{Acknowledgements}

The research reported herein was performed pursuant to a grant from the U.S. Social Security Administration (SSA) funded as part of the Retirement Research Consortium through the University of Michigan Retirement Research Center (5 RRC08098401-07). The opinions and conclusions expressed are solely those of the author(s) and do not represent the opinions or policy of SSA or any agency of the Federal Government. Neither the United States Government or any agency thereof, or any of their employees, makes any warranty, express or implied, or assumes any legal liability or responsibility for the accuracy, completeness, or usefulness of the contents of this report. Reference herein to any specific commercial product, process or service by trade name, trademark, manufacturer, or otherwise does not necessarily constitute or imply endorsement, recommendation or favoring by the United States Government or any agency thereof.

\section{Regents of the University of Michigan}

Michael J. Behm, Grand Blanc; Mark J. Bernstein, Ann Arbor; Laurence B. Deitch, Bloomfield Hills; Shauna Ryder Diggs, Grosse Pointe; Denise Ilitch, Bingham Farms; Andrea Fischer Newman, Ann Arbor; Andrew C. Richner, Grosse Pointe Park; Katherine E. White, Ann Arbor; Mark S. Schlissel, ex officio 


\title{
Occupations and Work Characteristics: Effects on Retirement Expectations and Timing
}

\begin{abstract}
Population aging and attendant pressures on public budgets have spurred considerable interest in understanding factors that influence retirement timing. A range of sociodemographic and economic characteristics have been shown to predict both earlier and later retirement. Less is known about the role of occupations and their characteristics on the work choices of older workers. Knowing more about the occupations that workers seem to stay in longer or leave earlier may point the way to policy interventions that are beneficial to both individuals and system finances. This project uses detailed occupational categories and work characteristics in the Health and Retirement Study (HRS) linked to information in the Occupational Information Network (O*NET) to examine compositional changes in occupations held by older workers over time; to provide some basic and interesting information about relationships between occupations and their characteristics and retirement expectations and outcomes; and to shed light on which occupations and associated characteristics might encourage or discourage longer working lives. There are large percentage changes (increases in decreases) in the percentage of older workers in occupations over time. Considering detailed, as opposed to aggregated, occupational categories yields interesting additional information. Jobs that HRS respondents say entail less physical effort, less stress, and jobs that have not increased in difficulty in recent decades, and those in which people can reduce hours if desired, are associated with longer work. While the traditional blue collar-retire earlier and white collar-work longer associations emerge, we find interesting exceptions that suggest fruitful directions for future research.
\end{abstract}

\section{Citation}

McFall, Brooke Helppie, Amanda Sonnega, Robert J. Willis, and Peter Hudomiet. 2015. “Occupations and Work Characteristics: Effects on Retirement Expectations and Timing.” Ann Arbor, MI. University of Michigan Retirement Research Center (MRRC) Working Paper, WP 2015-331. http://www.mrrc.isr.umich.edu/publications/papers/pdf/wp331.pdf

\section{Authors’ Acknowledgements}

The research reported herein was pursuant to a grant from the U.S. Social Security Administration (SSA), funded as part of the Retirement Research Consortium (RRC). The findings and conclusions expressed are solely those of the authors and do not represent the views of SSA, any agency of the federal government, or the University of Michigan. 
Younger cohorts of Americans report increasing likelihood of working to older ages. Explanations for this trend reflect to some extent changing financial and institutional realities (e.g., the importance of defined contribution pension plans, employer-sponsored health insurance), as well as personal characteristics, especially health status (e.g., Aaron \& Callan, 2011; Cahill, Giandrea \& Quinn, 2008). Other research examines the possible impact of characteristics of the work environment on retirement transitions (Angrisani, et al., 2013). Yet technological advances and globalization ensure an ever-changing work environment with different labor sectors advancing and declining over time (Autor, 2003). Very little research to date has addressed the composition of occupations and the changing nature of work itself to understand the trend toward working longer and, alternatively, the decision to leave the workforce at younger ages.

Understanding how and why people exit the labor force at older ages bears importantly on our ability to develop responsible and salutary retirement policy. For years, policy analysts have anticipated the retirement of the Baby Boomers and have sought policy options—including encouraging longer working lives—-to relieve the attendant pressure on public budgets. Likewise, the private sector increasingly recognizes the desirability of keeping older workers on the job. While, in previous generations, employers provided incentives to urge early retirement, the question in both the private and the public sectors has now become: What can we do to retain older people in the workforce? Indeed, Americans are working to older ages, yet it is not clear when and how to urge people to stay in the labor force in ways that are welfare improving. Despite decades of policies encouraging longer working lives, barriers to work at older ages remain (Abraham \& Houseman, 2008). Ideally, those who are near or at retirement age but want 
to keep working and are able to do so will have those opportunities. And those in poor health, ${ }^{1}$ or with stressful or physically demanding jobs, would be able to retire or have the option to transition gradually to retirement through part-time or bridge work.

What changes do we see in occupations over time? What do we know about each of these occupations and the older workers in them, and how might the job characteristics of different occupations affect work expectations and actual retirement timing in older workers? To answer these questions, we use information on occupations and work characteristics in the Health and Retirement Study (HRS), linked to detailed occupational information in the Occupational Information Network $\left(\mathrm{O}^{*} \mathrm{NET}\right)$ project database, to examine the influence of occupations and job characteristics over the past 20 years on workforce departure or retention. We see significant changes in the occupational composition and job characteristics of workers. We find striking variation in the relationship between occupations and longer work lives and earlier workforce departures. Job characteristics, both objectively and subjectively measured, are important predictors of work decisions. This information provides an important benchmark against which to measure future changes in occupations and the relationship between occupations and their characteristics and retirement behavior.

\section{Background}

Reversing the decades-long trend toward earlier retirement, Americans are beginning to work longer and are taking a variety of paths toward retirement (Cahill, Giandrea, \& Quinn, 2008; Quinn, 2010). Younger cohorts report increasing likelihood of working to older ages (Johnson, Butrica, \& Mommaerts, 2010). Part of this reversal stems from elimination of and changes to both public and private policies — especially through the 1980s — that had encouraged

\footnotetext{
${ }^{1}$ Nearly 25 percent of 65-74 year-olds experience significant health limitations that make working at older age difficult (Rehkopf, Adler, \& Rowe, 2011). And low-wage workers are more likely to be in poor health (Gueorguieva, et al., 2009).
} 
workers to retire at relatively young ages. Some changes, such as the ban on mandatory retirement ages and both state and federal age discrimination laws, reduced institutionalized discrimination against older workers (Neumark \& Song, 2013). Changes in Social Security law removed barriers to working longer, such as the Social Security earnings test (Haider \& Loughran, 2008) and built in incentives to longer work, for example, by increasing the age of eligibility for full Social Security retirement benefits (Gustman \& Steinmeier, 2013).

Factors that may encourage earlier workforce departure are clearly still in effect. The past 30 years have seen major changes to pensions. Since their emergence in the 1980s as a vehicle for retirement savings, defined contribution (DC) plans have come to dominate the private pension landscape and are increasingly replacing defined benefit (DB) pensions even in the public sector (Beshears, Choi, Laibson \& Madrian, 2011). Yet the presence of a DB pension plan remains a powerful incentive. Several studies demonstrate that the availability of a DB pension has the effect of lowering expectations of working longer (Mermin, et al., 2007) and of encouraging workforce departure (Aaron \& Callan, 2011). Other employer-provided benefits that supported younger retirement, such as retiree health insurance, have been reduced over that time as well. In short, policies encouraging longer work have simultaneously helped to increase choices for those who wish to work longer and have limited options for those who need or desire an earlier retirement. At the same time, various incentives continue to encourage earlier retirement for a large proportion of the population.

Researchers have sought to understand more about who works longer and who follows different retirement paths. For example, Aaron and Callan (2011) study work decisions of men and women ages 55 to 66 in the HRS. While they find that women are more likely to stop working than men, they find no racial difference in who works longer. While greater wealth is 
generally associated with leaving the workforce, those with more education are likely to work longer. The major factor associated with stopping work is poor health. Our models of work expectations and work choices incorporate these and other covariates that are commonly found to influence retirement plans when retirement is considered as part of the life-cycle model of labor supply. Given previous research and predictions of the family of recent, dynamic life-cycle models (e.g., Gustman \& Steinmeier, 2014; Laitner \& Sonnega, 2013), we expect that good health, higher education, and earnings will be associated with remaining longer in the workforce (and lower expectations of working longer), whereas presence of a DB pension and higher wealth will be associated in the opposite direction. Research also suggests that married women are likely to depart work at younger ages compared to unmarried men and women and married men (Szinovacz, 2010).

Fewer studies have examined the role of occupations in retirement timing. Aaron and Callan (2011) evaluate the effect of occupation types available in the HRS public data (testing 15 aggregated categories) and a range of job characteristics. They find no association of occupation type with the probability of retiring. However, reporting that work is very stressful is a highly significant predictor of leaving work; not so for physical effort (stooping and bending, and lifting heavy weight). As blue-collar jobs have decreased and white-collar jobs increased (Johnson, Mermin, \& Resseger, 2007), it may be that the physical demands of work are decreasing as a reason for retiring. Other studies find relatively modest effects of highly aggregated occupation categories on work decisions, but comparatively strong effects of work characteristics. We speculate that taking a closer look at the detail held within aggregate occupational categories and linking them directly to work characteristics may yield more insight into retirement expectations and behavior. 
The contributions of this work are fourfold: 1) to examine compositional changes in occupations held by older workers over time; 2 ) to provide some basic and interesting information about relationships between occupations and their characteristics and retirement expectations and outcomes; 3) to shed some light on which occupations and associated characteristics might encourage or discourage longer working lives; and 4) to share a methodology for creating consistent occupation coding for the HRS detailed occupational data over time and linking these to O*NET job characteristics.

\section{Data and Methodology}

We use data from the HRS, a nationally representative longitudinal study of the population older than 50 in the United States. Details are provided in Sonnega, et al. (2014). The HRS core interview gathers information about the occupations in which HRS respondents work, as well as job history and job characteristics. Data are currently available for the 11 core surveys fielded from 1992 until 2012, and include observations for more than 37,000 individuals.

The public-use version of HRS reports 17 occupational categories formed by aggregating the 900+ 3-digit detailed occupations that are available in the HRS restricted data, which we use in this paper. The occupational coding schemes in the restricted HRS data have changed over the years (Nolte, Turf, \& Servais, 2014). To ensure comparability over time and to balance analytic power with occupational detail, we use a coding scheme that is consistent over time and that aggregates across small, similar occupation groups to obtain 100 or more observations per occupation/occupation group whenever reasonable. This coding scheme was developed to use in conjunction with the O*NET data (below), and contains 192 separate occupations/occupational groupings derived from the more than 900 original occupational codes. As a product of this project, we are sharing the crosswalks used to create time-consistent occupation codes within the 
HRS and to link these to O*NET job characteristics. These can be accessed at:

https://sites.google.com/site/phudomiet/Occupation-Crosswalks-MRRC-2015.xlsx. ${ }^{2}$

\section{Study Measures}

$\underline{\text { HRS employment, subjective expectations, and job characteristic variables }}$

HRS contains self-reports about characteristics of the main occupation, specifically in our analysis, we use the degree to which the job requires a lot of physical effort, involves a lot of stress, and has gotten more difficult. We also included a measure of whether or not the employer would be likely to allow the respondent to reduce his or her work hours if desired. Our main dependent variables in the first set of regression analyses we present, the "subjective probability" questions about working full-time past age 62 and 65, have been asked in nearly identical form in the HRS since 1994. Manski (2004) has suggested that because "subjective probabilities," such as those measured in these questions, allow for expression of uncertainty, they are more closely linked to modern economic theory than point estimates. Several studies have validated the relationships between subjective probability data and actual outcomes (Hurd \& McGarry, 1995; Dominitz \& Manski, 1997; McGarry, 2004; Dominitz \& Manski, 2005; Hurd, 2009; Manski, 2004). Because they ask about future behavior, these measures capture a snapshot of retirement expectations that may be used for analysis prior to actual retirement. Changes in these expectations over survey waves can help researchers zoom in on the factors that move the expectations measures and, by extension, retirement behavior. We also combine information about occupation and age to create early retirement and late retirement indicators as the dependent variables in the final set of analyses.

Lastly we used a question in HRS that asks respondents, "On your main job, what is the usual retirement age for people who work with you or have the same kind of job?” For these

\footnotetext{
${ }^{2}$ This coding scheme was developed by Peter Hudomiet, who welcomes comments about this crosswalk.
} 
HRS job characteristic and expectation variables, we use data from the HRS Tracker file, HRS core survey data, and constructed variables from the RAND HRS data version N, a cleaned and ready-to-use version of the HRS data (Chien et al., 2014).

$\underline{\mathrm{O} N \mathrm{NET} \text { job characteristics }}$

The O*NET program, sponsored by the United States Department of Labor's Employment and Training Administration, provides detailed occupational information to researchers, students and the public. Using a combination of surveys, expert assessments, and tests, the O*NET database contains occupation-specific information on personal requirements (the skills and knowledge required to perform the work); personal characteristics (the abilities, interests, and values needed to perform the work); experience requirements (the training and level of licensing and experience needed for the work); job requirements (the work activities and context, including the physical, social, and organizational factors, as well as the tasks, tools, and technology involved in the work); and the labor market (the occupational outlook and the pay scale for the work). In this paper we focus on a subset of ability and activity measures that seem most important to retirement decisions while not overly collinear with the other measures. The O*NET database contains measures for 974 occupations. For each occupation, O*NET provides information on the level and importance of each required work activity. Following Firpo, Fortin, and Lemieux (2011), we use Cobb-Douglas weighted means to combine occupation-level importance and level measures. Importance weights are 2/3, level weights are 1/3. Given the smaller number of somewhat aggregated occupations in our HRS data, we average across multiple O*NET occupations that crosswalk to the HRS occupation categories to create O*NET measures for the HRS occupations. We use CPS detailed occupation frequencies to weight O*NET measures to the level of the 192 detailed occupation categories used in this paper. 
For this paper, we used O*NET information on the activities and abilities required for different jobs. Of the 18 activities included in our crosswalk, we selected nine to either represent a group of similar abilities and/or unique abilities that we hypothesized would be related to either workforce retention or departure. These include analyzing data or information; making decisions and solving problems; controlling machines and processes; interacting with computers; repairing and maintaining electronic equipment; documenting/recording information; assisting and caring for others; performing for or working directly with the public; coaching and developing others. Of the six ability measures included in our crosswalk, we selected mathematical reasoning and arm-hand steadiness.

\section{$\underline{\text { Covariates }}$}

Several regression models include a set of covariates that are commonly found to be predictive of retirement expectations and/or behavior. These HRS variables include self-reported health, coded as fair or poor (referent) or good, very good, excellent; vesting in a DB pension; gender and marital status coded as unmarried male (referent), unmarried female, married male, married female; log of total nonhousing wealth, and log of the respondent's labor earnings and educational attainment coded as less than high school (referent), high school, some college, and college graduate or higher.

\section{Analysis}

Our analysis proceeds in three main stages, each with somewhat different goals and, therefore, different samples.

The first stage of our analysis evaluates changes in occupational composition associated with earlier and later workforce departure among older workers over time. We begin with an analytic sample of HRS respondents who were 51 to 61 at their initial HRS interview. We 
include respondents from new cohorts that were added in 1998, 2004, and 2012. For simplicity in these descriptive analyses, we exclude respondents who were retired, who were self-employed, or who reported working part-time at their baseline HRS survey. To shed light on which occupations are associated with either increasing likelihood of earlier versus later workforce exit or differences in occupational employment patterns between cohorts, we calculate the average percent change in the fraction of workers in each occupation over time, from 1992/1994 to 2010/2012. For these analyses, we include all birth cohorts for the 192 aggregated categories, but exclude occupations with fewer than five observations in any core survey. We pool data from two consecutive core surveys for each end point to increase sample sizes, thereby increasing the chance that changes we see are due to actual compositional changes as opposed to noise. Because there were substantial occupation coding changes in the HRS data in 2010, we also provide the changes from 1992/1994 to 2006/2008.

In the second stage, we examine factors associated with subjective expectations of working full-time past age 62 (P62) and working full-time past age 65 (P65). For the analyses in this section using $P 62$ and $P 65$, we restrict to a single observation of each working HRS respondent at age 57 or 58 . This is early enough that most respondents have not yet retired, but is close enough to typical retirement age ranges to reflect somewhat realistic expectations about when respondents expect to retire. In 1992, the code frame for the subjective probability of work past age 62 and 65 was on an 11-point scale, while from 1994 onward it was 0-100 percent. Therefore, we begin these analyses with 1994, or wave 2. As with all analyses in this paper, we exclude HRS respondents who were already retired or were self-employed at their first HRS interview. We conduct descriptive statistics (Table 2.1) then a set of multivariate regression models beginning with a baseline model that includes a wave indicator along with demographic 
and economic covariates (Table 2.2). The next model, in Table 2.4, adds the public occupational categories to the baseline model (descriptive statistics for this analysis can be seen in Table 2.3). The excluded occupation in these regressions is managerial specialty operation. A third model adds the detailed occupational categories to the baseline model (Table 2.6, with descriptive statistics in Table 2.5). The excluded occupation in these regressions is financial managers. A final table adds the measures of usual retirement age to the model with detailed occupations (Table 2.7).

In our analysis of retirement expectations, we also conducted regressions of P62 and P65 on occupational category, survey wave, and the interaction between these two to investigate possible changes in the relationship between P2/P65 and occupation type over time. These results are discussed in the text only, but tables are available upon request.

Finally, we also conducted a set of regressions that add HRS job characteristics or O*NET variables to the baseline model with covariates. In some specifications with HRS job characteristics, we also include detailed occupations. Because of their collinearity with detailed occupation indicators, the regression with $\mathrm{O} * \mathrm{NET}$ characteristics included baseline covariates only. Again, these results are discussed in the text only, but tables are available upon request. In the third stage of our work, we begin to look at snapshots of occupations associated with longer working lives. Recall that our data include respondents from new cohorts that were added in 1998, 2004, and 2010; however, no one who was between ages 51 and 61 in 2010 would have aged into the 66+ age range by 2012, so they are effectively excluded.

There are many different ways to define retirement timing variables. For purposes of this paper, we have created two binary variables, early retirement and late retirement. To create these indicators, we use the last observed occupation in the HRS data to date the year of last work. We 
then calculate the respondent's age at that interview to categorize the respondent. ${ }^{3}$ Early retirement is equal to one if the last observed occupation was before the respondent reached age 63 and zero if it was at age 63 or older. Late retirement is equal to one if the last observed occupation was after the respondent reached age 66 and zero if before.

For those respondents who were retired at the most recent (2012) wave of the HRS, the presence of a nonmissing occupation code aligns closely with respondents' stating that they are working and not completely retired. A small fraction of respondents report themselves to be not working despite reporting a job. The last nonmissing occupation code is often one-two years earlier than the variable for year of last occupation in the RAND Version $\mathrm{N}$ dataset, ${ }^{4}$ but is available for even nonretired respondents, so does not introduce as much of the censoring inherent in other measures of retirement timing such as age of retirement. For analyses using these variables, we restrict the sample to respondents who were age 66 or older by the time of their last HRS interview, whether that took place in 2010 or before. As such, we are able to categorize all respondents who were alive at age 66.

Note that both the early retirement and late retirement indicator variables can be assigned even if respondents reported still working at their last HRS interview. Thus, these variables are less affected by censoring than traditional "retirement age" variables. As with other measures of retirement age, these measures are not proof against "unretirement" in years after the last observation. Additionally, the last observed occupation may represent either a career job or a bridge job. Exploration of such nuances is beyond the scope of the current work.

A useful way to consider these variables is to look at the percentage within each occupation that does not retire early (Table 3.1 uses the early retirement indicator, and Table 3.2

\footnotetext{
${ }^{3}$ Missing birth months were assumed to be June. All birth dates and interview dates were assumed to take place on the $15^{\text {th }}$ of the month.

${ }^{4}$ In future work, we will explore altering the date of last occupation to match last job date.
} 
uses the late retirement indicator), which we present for the 10 most common detailed occupational categories, the 10 with the highest rates of last occupation observed at 66 or later (excluding most common occupations) and the 10 occupations with the lowest rates of last occupation observed at age 66 or later (again excluding the most common). We exclude observations for which we are missing the occupation code for the last/most-recently held job. The number of observations has been masked for occupations with fewer than 10 observations in this year.

We then run linear probability model regressions (OLS) with early retirement or late retirement indicators (0/1) as dependent variables and occupation indicators as regressors to explore correlations between these retirement variables and specific occupations toward the end of working life. For these analyses, we use all data from 2010 for respondents who were 51 to 61, working full-time, and not self-employed at their baseline interview, and older than 66 in 2010. The excluded occupation in these regressions is financial managers. Only occupations that were statistically significant in one of the two regressions are presented in the tables. Full tables are available upon request.

We examine job characteristics of the occupations, both self-reported by HRS respondents and from the linkage to $\mathrm{O} * \mathrm{NET}$ characteristics, and their relationship to retirement timing. In Table 3.4, we present summary statistics for these variables including mean, median, and $25^{\text {th }}$ and $75^{\text {th }}$ percentiles. Lastly we run a series of linear probability models to examine the relationships between our retirement timing indicators and detailed occupation, self-reported job characteristics, and O*NET job activities and abilities, simultaneously. (Because O*NET job characteristics are linked to each occupation, they are highly collinear with occupation indicators and should not be included in the same regressions.) 
Tables 3.5, 3.6, and 3.7 present results from linear probability models regressing early retirement or late retirement indicators on various combinations of job characteristics and, in Table 3.5, occupation indicators. Specifically, Table 3.5 includes the HRS self-reported job characteristics and occupation indicators as covariates. The first and second columns of this table report results using the dependent variable early retirement, while the third and fourth columns report results using late retirement. As with the previous regression analyses, the occupation financial managers is the base occupational category. Additionally, to reduce table length, we present only results for occupations whose coefficients were statistically significant in at least one of the models. Again, respondents are included in this regression only if they were 66 or older at the time of the last observation. Tables 3.6 and 3.7 present results using job characteristics only, both from O*NET and the HRS self-reports, as independent variables. The dependent variables are the early retirement and late retirement indicator variables (Tables 3.6 and 3.7, respectively).

\section{Results}

1. Changes in occupational distributions over time may indicate longer working versus earlier departing occupations or inter-cohort differences in occupational employment.

We begin by characterizing the changes in occupational composition of HRS respondents over time. Note that this analysis requires respondents to be between 51 and 61 and working fulltime at the point of their enrollment interview. Table 1.1 shows the occupations with relatively large percentage changes over time in the fraction of older workers in the detailed occupations, relative to other occupations. For brevity, we report the top 10 occupations where we see the most change toward lower employment at older ages, and the top 10 where we see the most change toward greater employment at older ages. The former group of occupations are simply 
those held by a decreasing proportion of older workers in 2010/2012, relative to 1992/1994. As noted, we present results for changes at 2006/2008. Both sets of results tell similar stories. A large decrease in the proportion of older workers in an occupation could indicate that workers in this occupation tend to retire or switch to other jobs at younger ages than other workers. However, it could also mean that a particular occupation was more common among the older HRS cohorts than the younger ones at similar ages, and that the younger groups did not move into that occupation as the older group retired or moved into other occupations.

Examples of some of the larger occupations in which we see decreased occupational employment among older workers over time include other managers, other machine operators, and other freight, stock and material handlers. While the latter two occupations, and, indeed, a majority of the occupations in the upper portion of the table, are blue-collar jobs which are more likely to be unionized and offer DB pensions and stronger early retirement incentives than whitecollar jobs, the other managers is the single largest occupational category, and it seems more likely that these jobs are white-collar jobs. In this sense, some of the entries in this table seem surprising, while others align well with the idea that workers in blue-collar jobs choose, are incentivized, or need to retire early, relative to those in other jobs.

In the bottom half of Table 1.1, we see occupations in which a larger proportion of HRS respondents were working in 2010/2012 than in 1992/1994. Again, the meaning of the percent changes is ambiguous: It could be that a large increase in the proportion of older workers in an occupation means that these workers tend to retire later. It could also be that these are popular bridge jobs, or that these are jobs that are more common among younger HRS cohorts than those in older cohorts, even if compared at the same ages. Here, we see many of the expected "white 
collar” jobs which are likely to require high levels of education and are not particularly physically challenging, increasing the likelihood of longer work.

These, however, are likely difficult to enter at later ages from an unrelated career track, so are not likely to be bridge jobs or to provide new opportunities to those looking to move from a more physical job to something they can do longer. However, there are also a few occupations which do not fit this pattern, such as teacher assistants; customer service representatives; investigators and adjusters, except insurance; gardeners and groundskeepers; and taxi cab drivers and chauffeurs. Each of these occupations is at least twice as common in 2010/2012 among older workers than in 1992/1994. It could be that individuals in these occupations, either due to financial necessity or love of the job, tend to work to later ages. Unlikely though it seems, it could also be that these are more common jobs among the younger HRS cohorts. Perhaps a more attractive explanation, and one that we plan to explore further in the future, is that these are common "bridge" jobs that older workers transition to rather than retiring completely. If this last explanation is true, these are particularly interesting occupations, because they are occupations which one can imagine that many older workers might be qualified to do, even if their work history is largely or completely unrelated. In the next two sections, we focus on the relationship between retirement and occupation more directly.

\section{Who expects to work longer?}

We now turn to examining the relationship between occupations (both detailed and public), job characteristics (O*NET and HRS), usual retirement age, and P62 and P65. In Table 2.1, we present a set of summary statistics for $P 62$ and $P 65$ and the baseline covariates used in the ensuing regression models. We present descriptive statistics for the sample used to conduct the regression of $P 62$ only since the sample from the $P 65$ regressions is very similar. In this 
sample of workers aged 57 to 58 , the average probability of working past age 62 is about $51 \%$ and working past age 65 is $29 \%$. The mean wave value of about six suggests that there is a fairly even distribution of observations from the earlier and later waves of the HRS. A large fraction of respondents reported good or better health, which is not surprising given the selection criteria. Forty-five percent of the sample reported entitlement to a $D B$ pension. The fraction of the sample that is female is only 45 percent, again, not surprising given the sample.

Table 2.2 presents results from regressions of $P 62$ and $P 65$ on the baseline covariates. The wave variable captures linear time trends in retirement expectations; due to the general increase in working to later ages in recent years, we expect this coefficient to be positive but not large. Similarly, we expect good health or better to be positively associated with the likelihood of later work, and entitlement to a $D B$ pension to be negatively associated with likelihood of later work. We expect wealth (log total nonhousing wealth) to be negatively related to the likelihood of later work, while labor earnings (log earnings) are expected to be positively related. Higher education levels are expected to be positively related to longer work, due to higher earnings, lower physical demands of jobs, and perhaps greater control over one’s work life. Marital status and gender are also likely to be related to retirement expectations: We expect that unmarried women are more likely to work longer due to greater financial need, and married women to plan to retire earlier to line up their retirement with that of their generally older husbands.

Indeed, we find that our hypotheses are borne out quite clearly in our baseline linear regression results, with regression coefficients of the expected signs and mostly of nonnegligible magnitudes. However, the predictive power of these regressions is fairly small, leading us to ask whether occupations and occupational characteristics may provide added value in predicting HRS respondents' expectations of working past 62 and 65. 
We next turn to the HRS RAND public occupational categories to see what may be gained, relative to the regressions without occupational information. Specifically, we add 17 indicator variables for the large occupational category in which respondents reported working at the age of 57 or 58 . Changes in the coding scheme over time reduce the number of waves for which we have a substantial number of observations, so these regressions only use data from 1992 through 2006. Table 2.3 shows summary statistics for these public occupational categories across P62 and P65, which demonstrates some variation in work expectations across the public categories: However, it seems likely that these large categories may mask larger variation that may be seen in the detailed occupations.

Table 2.4 presents results from the regression of $P 62$ on the baseline covariates along with the RAND public occupational categories. The first two columns show the regression coefficients and standard errors in the model using $P 62$ as the dependent variable, while the latter two columns are for P65. Qualitatively, adding the public occupational categories does little to change the effects of the baseline covariates. The only exceptions are that the coefficient on the married and female indicator variable is no longer statistically significantly different from zero in the $P 62$ regression, and college+ is the only statistically significant education indicator. These models explain a similar proportion of the variance in P62 and P65 as the baseline regressions with only the covariates and wave indicator. The coefficient signs on the set of baseline covariates are also the same. Magnitudes are similar, though slightly reduced, and statistical significance patterns are largely consistent but slightly less robust when compared with the baseline regressions. Several of the large occupational categories do, however, display strong partial correlations with the dependent variables $P 62$ and $P 65$. In many cases, the coefficients are on the order of 10 to 20 percentage points, rivaling or exceeding the partial effect of DB pensions 
and college completion. In particular, provision of private household, cleaning and building services; protective services; health services; and operators: handlers, etc., are negatively related to $P 62$ and $P 65$.

In the P62 regression, construction trades and extractors; machine operators; and transportation operators also tend to report lower probabilities of full-time work past 62, and precision production workers report lower probabilities of full-time work past 65 . These results imply that occupation, or occupational characteristics, aside from pensions and earnings, are important predictors of retirement expectations. Next, we substitute the public occupation variables with our detailed occupation indicators, to see if more detailed occupational categories add additional predictive power to these regressions and additional insights into the relationship between occupation and retirement expectations.

We first present summary statistics for $P 62$ and $P 65$ for each of the detailed occupational categories (Table 2.5). Results are provided for all occupations. Cell counts (and percentages) are masked for categories with fewer than five observations. For larger occupational groups, which may represent more reliable estimates, the mean values vary considerably across occupations for both $P 62$ and $P 65$. For example $P 62$ ranging from 39 percent for primary school teachers (category 31) to 58 percent for other sales and sales related (category 69). Perhaps even more interesting is the $75^{\text {th }}$ percentile. Here, for a large number of occupations, it can be seen that more than a quarter of respondents report a 100 percent probability of full-time work past age 62. On the other hand, looking at $P 65$, even at the $75^{\text {th }}$ percentile cut-off, respondents in most occupations are reporting much lower probabilities of working past age 65. Nonetheless, a smaller number of relatively less common occupations report very high expected probabilities of working past age 65 . 
Table 2.6 presents results from regressions of $P 62$ and $P 65$ on baseline covariates plus detailed occupation indicators. In these models, the signs, magnitudes, and significance patterns of the baseline covariates are, again, qualitatively very similar to those in the baseline regression table. As in the table with public occupation categories, of the education categories, only the coefficient on college+ is precisely estimated (as opposed to both some college and college+ in the baseline regressions). Log earnings and good health or better also lose their statistical significance, relative to the baseline regression for $P 65$.

Turning to the estimated coefficients for the detailed occupational indicators in Table 2.6, we see an interesting pattern: Every statistically significant coefficient, and a vast majority of those that are not statistically significant, is negative and fairly large relative to the referent category (financial managers). That is, the common pattern for occupations is that, if they are associated with the probability of full-time work past 62 or 65, the relationship is negative. Of occupations with at least 50 observations in this sample, we see strong relationships for primary school teachers, secondary school teachers, other matchine operator,s and janitors for both the $P 62$ and P65 regressions. This suggests that attempting to reduce occupation-specific factors that encourage earlier retirement expectations in many occupations may be more effective than encouraging transition to occupations in which later work is the norm in reducing early Social Security claiming and/or old age financial insecurity. This pattern is also broadly consistent with our results on actual retirement timing in the next section.

Overall, comparing across results from Tables 2.3/2.4 and Table 2.5/2.6, we find considerably more variation in $P 62$ and $P 65$ in the detailed occupational categories relative to the aggregated public occupational categories. 
Next, we explored the role of respondents' reports of usual retirement age in their jobs on retirement expectations. Table 2.7 presents results from two regressions, both with $P 65$ as the dependent variable. In the first set of regression results, we added usual retirement age in the respondent's job at age 57/58. A one-year increase in the usual retirement age is associated with about a 1.8 percentage point increase $(\mathrm{p}<0.001)$ in the chance a respondent expects to be working full-time past age $65 .{ }^{5}$ Coefficients on our standard covariates remain qualitatively similar to our other models including detailed occupation. Here, again, we see that all statistically significant coefficients on occupation indicators are negative and fairly large in magnitude.

Because one response category to the question about usual retirement age in one's job was "no usual age," we have also included an indicator for this response as a regressor in the second model presented in this table. This increases the sample size for this regression substantially, and this variable is found to be statistically significant and to indicate a 6.5 percentage point increase $(\mathrm{p}<0.001)$ in the probability of work past age 65 for respondents reporting that there is no usual age of retirement in their jobs. Other results are qualitatively unchanged from the first two columns of the table, and also similar to other regressions of the probability of full-time work past 65 on similar sets of covariates. A perceived later usual retirement age in a job or the lack of a norm both appear to have important bearing on retirement expectations, but neither seem to systematically affect the coefficient estimates of the occupation dummies.

We then conducted several further models, for which results are not presented, but areavailable upon request. In addition to examining the relationship between occupation and

\footnotetext{
${ }^{5}$ Adding only the usual retirement age variable along with the baseline covariates we've been using in this set of regressions also shows that a one-year increase in the usual retirement age is associated with about a two percentage point increase $(\mathrm{p}<0.001)$ in the chance a respondent expects to be working full-time past age 65 . Inclusion of this variable alone increases the adjusted R-squared from 0.09 in the baseline regression to 0.12 .
} 
retirement expectations, we also conducted regressions that interacted occupation with wave. The dependent variables in these analyses were P62 and P65. Again, the sample was restricted to HRS respondents who were working when they were interviewed at age 57/58. The covariates included in this model were the same as the baseline model in Table 2.2. In the first set of regressions, the RAND HRS public occupation indicators were included and interacted with wave. Qualitatively, the results for the covariates were very similar to those in Table 2.4 in terms of magnitudes, signs, and statistical significance. The one qualitative change, relative to that table, is that farming/fishing/forestry became statistically significant once the occupation $\mathrm{x}$ wave interactions were also included.

The wave indicator variables did not show a consistent pattern over time: Most were not statistically significant, and the signs and magnitudes changed nonmonotonically from wave to wave. Coefficients on mechanics/repair by wave generally get smaller over time (moving from positive and fairly large to slightly negative), and coefficients on both construction trade/extractors and precision production by wave seem to generally increase over time, but none exhibit clear, statistically significant patterns. Overall, after adjusting for the number of covariates, these regressions explain only marginally more variance in work expectations than regressions without the occupation by wave interactions (adjusted R-squared values are 0.07 for P62 and 0.09 for P65). As in any regression with many covariates, it is possible that sample size is limiting our ability to detect true changes over time within work expectations by occupation.

In the second set of regressions, we included indicator variables for 15 large, detailed occupational categories: those with at least 50 observations in the sample used in the first regression of $P 62$ on detailed occupation indicators and baseline covariates. We used only 15 occupations for parsimony, since the interactions would greatly increase the number of variables 
in the regression. Qualitatively and quantitatively, we see very similar results to those with detailed occupation but no wave interactions. The coefficients on janitors, nursing aides, office supers and secretaries lost statistical significance relative to other detailed occupational regressions, but did not change in sign. Nurses may have reported increasing probability of working past 65 over time, but this pattern is not statistically significant. Both the R-squared and adjusted R-squared are smaller here than in regressions with the full set of detailed occupations. Overall, it appears that we are constrained by sample size issues even after restricting to only the largest occupational categories.

We further conducted analyses of the HRS job characteristics and O*NET variables, for which tables are available upon request. In regressions of $P 62$ or $P 65$ on HRS job characteristics, either with or without covariates and occupation codes, there is no strong pattern of significance. Furthermore, these variables leave the rest of the regression results qualitatively (and mostly quantitatively) unchanged. This has interesting implications. For example, it could be that specific, current job characteristics at age 57/58 do not greatly affect one's plans for retirement, but do impact actual retirement timing.

In regressions of $P 62$ on the $\mathrm{O}$ *NET variables and covariates, the estimates for the covariates are qualitatively similar to other specifications in this paper. Here, coefficients on the activity documenting and recording information and the ability arm-hand steadiness are negative and statistically significant, while the ability mathematical reasoning is positive and statistically significant. None of the coefficients on the other eight activities and abilities included in this regression is precisely estimated. The adjusted R-squared for this regression is 0.14 , showing some added explanatory power of this set of O*NET variables relative to the baseline regression. 
In the $P 65$ model with covariates, only one O*NET variable is statistically significant, namely, performing for or working directly with the public, which is positively related to the probability of working past age 65 . The adjusted R-squared for this model is 0.13 .

3. Who remains longer at work and who departs earlier?

We now turn to examining the relationship between occupations (both detailed and public), job characteristics ( $\mathrm{O}$ NET and HRS), and earlier and later workforce departure. In these analyses, we use data from respondents who were older than 66 in 2010 to better understand which occupations are associated with later work. This removes the concern that differences in how common an occupation is between cohorts is driving the results, as was a possibility in Table 1.1. Respondents are assigned the occupation in which they last worked, if they were no longer working as of the 2010 HRS interview, and the occupation in which they were working as of the 2010 interview, if they were still working.

Tables 3.1 and 3.2 use data from HRS respondents who were older than 66 in 2010, and report the percentage of workers within occupations who do not retire early for the 10 most common detailed occupational categories, the 10 with the highest rates of last occupation observed at older ages (excluding most common occupations), and the 10 occupations with the lowest rates of last occupation observed at older ages, again excluding the most common. The second column of each table reports the number of observations in each occupational category, so one can get a sense of how common each occupation is. Table 3.1 uses the early retirement indicator, which indicates whether a respondent's last observed occupation was observed before or after age 63. Table 3.2 uses the late retirement indicator, which indicates whether a respondent's last observed occupation was observed before or after age 66. Overall, these reflect similar patterns found in Table 1.1, with mostly blue-collar jobs showing the lowest rates of later 
retirement, and both highly-skilled professional jobs and jobs such as taxi drivers, messengers, and protective services workers showing higher rates of later work. For occupations showing similar tendencies in Tables 1.1, 3.1, and 3.2, it is likely that the explanation for trends in Table 1.1 is due to retirement patterns rather than compositional differences between cohorts.

Table 3.3 reports results from the linear probability model regressions of early retirement and late retirement on the occupation dummies. Results in this table are similar to those in Tables 3.1 and 3.2. Recall that these analyses include data from 2010 for respondents who were 51 to 61, working full-time, and not self-employed at their baseline interview and were older than 66 in 2010. The excluded occupation is financial managers. Coefficients for occupations that were statistically significant in one of the two regressions are presented in the tables. Not surprisingly, some of the occupations most significantly predictive of early retirement include production supervisors or foremen, other machine operators, precision metal workers. Yet we also see purchasing managers; agents and buyers; and business and promotion agents retiring earlier. Perhaps less surprising, we find that licensed practical nurses are more likely to retire earlier, as well. Occupations where recent workers seem to be remaining longer include management analysts; postsecondary teacher; social workers, clergy and religious workers; lawyers and judges; writers, authors, and technical writers; designers, musicians or composers; real estate sales; messengers; taxi cab drivers and chauffeurs; guards, watchmen and doorkeepers; and other protective services. Thus, workers in a wide range of occupations appear to be remaining at work longer, potentially for a wide range of reasons.

Table 3.4 presents summary statistics for the job characteristic variables, as well as the early retirement and late retirement variables for the sample in the analyses in Tables 3.5, 3.6, and 3.7. The means of the early retirement and late retirement indicators, at 0.38 and 0.45 , are 
very similar to those used in Tables 3.1, 3.2, and 3.3. Again, the majority of respondents appear to finish working in the age range of 63 through 65 , despite the modal age of last work at 62 . The means and distributions of the four HRS job characteristic variables show a fair amount of variation, so they are likely to meaningfully differentiate between occupations if individuals' views of the same occupations tend to agree. Most respondents in their final observed occupations tend to slightly disagree that their jobs are more difficult than they used to be, and that their jobs involve a lot of stress. Additionally, most respondents' last-observed occupations seem not to be particularly physically demanding. This is encouraging from the perspective of encouraging later work, since physically-demanding jobs may be difficult or impossible to continue in at later ages. Most respondents report that they could not reduce their work hours if they wanted to, indicating a lack of flexibility in the work hours of most jobs that has been confirmed by other studies. The O*NET variables have tighter ranges but display some variability, nonetheless.

Tables 3.5, 3.6, and 3.7 explore the relationships between occupational characteristics and retirement decisions. Table 3.5 presents regressions of early retirement and late retirement indicators on HRS job characteristics and detailed occupation indicators. The R-squared from these regressions are fairly high, higher than in the regressions that do not include the HRS job characteristic variables. This implies that there may be significant value in the HRS job characteristic variables in explaining retirement behavior, above and beyond what is common to particular occupations. That is, individuals' experiences in their particular jobs are not fully summarized by their job titles. Each of the HRS variables are highly statistically significant, with higher values of each (disagreement that job is more difficult than it used to be, disagreement that job is stressful, less physical demands of job, and the ability to reduce hours if desired) being 
associated with a lower probability of early retirement, and a higher probability of later retirement. All coefficients are of the expected signs. For example, the ability to reduce one's work hours is associated with a 16 percentage point increase in the probability of working past 66, and a 16 percentage point decrease in the probability of stopping work prior to age 63 , all else equal.

Moving from strongly agreeing to strongly disagreeing that one’s job is very stressful decreases the chance of early retirement by 21 percentage points, and increases the chance of late retirement by 24 percentage points, all else equal. The coefficients on the occupation indicators are at least as large as these, implying that there is, indeed, a fair amount of commonality within occupation that is associated with retirement timing. However, in a sense, the coefficients on the occupation indicators are simply unlabeled residuals, the contents of which we have yet to understand. What they tell us at this stage is that there is something about some of these occupations that influences retirement timing that is not captured by the HRS variables.

Tables 3.6 and 3.7 present regressions of early retirement and late retirement, respectively, on job characteristics. Recall that these do not include the occupation indicators because of their collinearity with O*NET variables. Rather, the point of these analyses is to examine the relative value of the O*NET versus HRS job characteristic variables. Both tables support the observation that respondent-reported HRS variables appear to be much more important than O*NET variables, over all. For example, the adjusted R-squared for the model predicting earlier retirement with only self-reported job characteristics is 0.10 , increasing to 0.12 with the addition of the O*NET variables. Likewise, predicting later retirement, the adjusted Rsquared for the HRS variables only is 0.11 and 0.15 with $\mathrm{O}$ *NET included. It may be that perceptions of one's job, or idiosyncrasies of particular jobs at particular firms are not well- 
captured by occupation-level variables. On the other hand, in these analyses we have aggregated across several occupations, which may attenuate the association. It also seems likely that the correlations between the $\mathrm{O}$ *NET variables may be causing them to cancel one another. We attempted to choose as independent a set as possible, but the correlations between these characteristics are still all above 0.3 (and mostly above 0.5 ).

\section{Conclusion}

The findings of this study represent preliminary steps in beginning to exploit the rich data resource of the detailed occupational categories in the HRS as an avenue to understand more about longer working lives in the United States. It is important to recall that these analyses exclude respondents who were retired or were working part-time at the time of their initial HRS interview. Thus, these results should not be construed as representative of older adults as a whole. However, as the goal of this project is to shed some light on trends in occupational composition over time and how occupation and occupational characteristics may be related to retirement expectations and timing, we believe these analyses provide interesting descriptive information that points the way to areas for future work.

Our goal with this initial work is to look at compositional changes in employment of older workers over time, highlighting some occupations that may be retiring earlier (or may be less common in younger cohorts) or that may be retiring later (or may be more common in younger cohorts). Our results tend to show that more blue-collar jobs have the largest decreases in percentage of older workers in occupation, relative to older workers in all occupations. The range of occupations found in the largest increases reflects mostly white-collar jobs but also includes occupations such as taxi drivers and farm operators. When we specifically model early and late retirement, we find interesting differences in which occupations are likely to be 
associated with longer work lives and earlier workforce departures. Many results are as expected. For example, we find white-collar, especially creative or labor-of-love-type jobs such as clergy or writers/authors and/or those that are not physically demanding, common in longerworking occupations. However, we also find occupations such as taxi drivers and chauffeurs, guards and watchmen, and messengers as jobs where people are working past age 66. These are jobs that many people may have the qualifications to do. In some cases, they provide flexible hours, which many older workers find appealing, as well as opportunities for social engagement, which appears to be especially important for well-being at older ages.

We also sought to share some basic and interesting information about relationships between occupations and retirement expectations, and to shed some light on which occupations and associated characteristics might encourage or discourage longer working lives. As expected, we find considerably more variation in the P62 and P65 outcomes by detailed occupations compared to the public occupations, suggesting that further exploring of the detailed occupations is likely to be a fruitful direction. We found an interesting pattern of results in the regressions using the detailed occupations: If the occupation was statistically significantly associated with the expectations of working longer, the relationship was negative. These patterns also held in the analyses of actual retirement. This suggests increased attention be paid to identifying characteristics of occupations that encourage earlier retirement rather than just longer working. In the end, this may be a comparatively easier route to improving system finances than efforts to move workers to occupations in which later retirement is normative. Indeed, our analyses suggest that occupations where respondents report an older "usual age" or "no usual age” of retirement do have higher expectations of working past 65 . These norms, however, may be associated with less mutable aspects of the occupations. 
Interestingly, job characteristics, both objectively (O*NET) and subjectively (HRS) measured, were found to be important predictors of both early and late retirement outcomes, but were not consistently associated with expectations of working past 62 and 65. In the early and late retirement analyses, we found that after accounting for occupational category, jobs that HRS respondents say entail less physical effort, less stress, and jobs that have not increased in difficulty in recent decades, and those in which people can reduce hours if desired, are associated with longer work. These analyses, however, did not include the baseline covariates, largely because they are mostly time-varying, and it is not clear what wave to select for their inclusion. Our next steps will include potentially using a Cox proportional hazards approach to enable us to use time-varying covariates such as self-rated health and wealth to predict retirement. It is possible that their inclusion will diminish the effects of job characteristics, but is not likely to eliminate it.

It is possible that job characteristics and retirement norms may differently affect retirement over time. To examine this possibility, we attempted to evaluate the interaction of wave by occupations in models of job characteristics and usual retirement age. The sample size was too limited, however, to be confident in these results.

Going forward, we would like to complement these results with something like case studies of particular occupations to try to figure out what it is about them that seem to encourage earlier or later retirement. For example, identifying characteristics of occupations associated with earlier retirement could point to potential targets for policy intervention. It will also be useful to attempt to determine exactly which occupations reflect bridge jobs (rather than just longer-held career jobs), as workers increasingly pursue this path to retirement. It would be especially interesting to learn about which occupations are easier to enter at older ages, even without very 
specific education or training. This might point to occupations that may be potentially open to people who have retired from their career jobs. In sum, the descriptive findings presented in this paper just begin to explore these rich data resources of the detailed occupation data in the HRS and the possibilities for learning about the relationships between occupational characteristics and retirement timing. 


\section{References}

Aaron, H. J., \& Callan, J. M. (2011). Who retires early? Working Paper 2011-10. Center for Retirement Research at Boston College: Boston, MA.

Abraham, K.G. \& Houseman, S.N. (2008). Removing barriers to work for older Americans. In A Future of Good Jobs? America's Challenge in the Global Economy, Timothy J. Bartik, Susan N. Houseman, editors. Kalamazoo, MI: W.E. Upjohn Institute, pp. 161-202.

Angrisani, M., Hurd, M.D., Meijer, E., Parker, A.M., Rohwedder, S. (2013). Labor force transitions at older ages: The roles of work environment and personality. Working Paper 2013-295 Michigan Retirement Research Center: Ann Arbor, MI.

Autor, D.H., Levy, F. \& Murnane, R. J., (2003). The skill content of recent technological change: An empirical exploration. Quarterly Journal of Economics 116 (4), 1279-1333.

Beshears, J., Chois, J.J., Laibson, D. \& Madrian, B.C. (2011). Behavioral economics perspectives on public sector pension plans. Journal of Pension Economics and Finance. 10(2): 315-336.

Cahill, K. E., Giandrea, M. D., \& Quinn, J. (2008). A micro-level analysis of recent increases in labor force participation among older workers Working Paper (Vol. 8). Center for Retirement Research at Boston College: Boston, MA.

Chien, S., Campbell, N., Hayden, Hurd, M., Main, M., Mallett, J., Martin, C., Meijer, E., Miu, A., Moldoff, M., Rohwedder, S., St.Clair. P. (2014). RAND HRS Data Documentation, Version N. Santa Monica, CA: RAND Center for the Study of Aging.

Dominitz, J. \& Manski, C.F. (1997). Perceptions of economic insecurity: Evidence from the Survey of Economic Expectations. Public Opinion Quarterly, 61:261-287.

Dominitz, J. \& Manski, C.F. (2005). Measuring and interpreting expectations of equity returns. National Bureau of Economic Research Working Paper Series, No. 11313.

Firpo, Sergio, Nicole M. Fortin, and Thomas Lemieux. (2011). Occupational tasks and changes in the wage structure. IZA Discussion Paper No. 5542.

Gueorguieva, R., Sindelar, J. L., Falba, T. A., Fletcher, J. M., Keenan, P., Wu, R., \& Gallo, W. T. (2009). The impact of occupation on self-rated health: Cross-sectional and longitudinal evidence from the Health and Retirement Study. The Journals of Gerontology Series B: Psychological Sciences and Social Sciences 64(1), 118-124.

Gustman, A. L., \& Steinmeier, T. L. (2014). Integrating retirement models: Understanding household retirement decisions. Research in Labor Economics 80: 81-114.

Gustman, A. L., \& Steinmeier, T. L. (2013). Effects of Social Security policies on benefit claiming, retirement and saving Working Paper 19071. Cambridge, MA: National Bureau of Economic Research.

Haider, S.J. \& Loughran, D.S. (2008) The effect of the Social Security earnings test on male labor supply: New evidence from survey and administrative data. Journal of Human Resources, 43(1), 57-87

Hurd, M. (2009). Subjective probabilities in household surveys. Annual Review of Economics, 1(1):543-564.

Hurd, M. \& McGarry, K. (1995). Evaluation of the subjective probabilities of survival in the health and retirement study. Journal of Human Resources, 30:S268-S292. 
Johnson, R. W., Butrica, B. A., \& Mommaerts, C. (2010). Work and retirement patterns for the G.I. generation, silent generation, and early boomers: Thirty years of change. Working Paper (Vol. 8). Boston, MA: Center for Retirement Research.

Johnson, R.W., Gordon B. T. Mermin, \& Resseger, M. (2007). Employment at older ages and the changing nature of work. AARP Public Policy Institute Report 2007-20. Washington, DC: AARP.

Laitner, J.L. \& Sonnega A. (2013). Economic theories of retirement. In Oxford Handbook of Retirement, Oxford University Press (ed. Mo Wang). New York: Oxford University Press, pp. 136-151.

Manski, C.F. (2004). Measuring expectations. Econometrica, 72(5):1329-1376, 2004.

Mermin, G. B., Johnson, R. W., \& Murphy, D. P. (2007). Why do Boomers plan to work longer? Journals of Gerontology B: Psychological Science and Social Science, 62(5), S286-94.

Neumark, D., \& Song, J. (2013). Do stronger age discrimination laws make Social Security reforms more effective? Journal of Public Economics, 108, 1-16.

Nolte, M.A., Turf, M., \& Servais, M. (2014). Occupation and industry coding in HRS/AHEAD. HRS user guide. University of Michigan, Ann Arbor.

Rehkopf, D., Adler, N., and Rowe, J. (2011). Socioeconomic, Racial/Ethnic and Functional Status Impacts on the Future U.S. Workforce. Paper prepared for the National Research Council Committee on the Long-Run Macroeconomic Effects of the Aging U.S. Population.

Szinovacz, M. (2010). Gender and marital status differences in retirement planning. Gerontology Institute Fact Sheet. University of Massachusetts Boston.

Sonnega, A., Faul, J., Ofstedal, M.B., Langa, K., Phillips, J., \&Weir, D. (2014). Cohort profile: the Health and Retirement Study (HRS). International Journal of Epidemiology, 43, 576585.

Quinn, J.F. (2010). Work, retirement, and the encore career: Elders and the future of the American workforce. Generations: Journal of the American Society on Aging, 34 (3), 4555. 
Table 1.1. Compositional changes in occupation: occupations displaying large changes in employment of older workers over time, all cohorts

Total these 20 occupations, 1992-2012 7,140

Total for 192 occupations with min 5 observations, 1992-2012

28,624

\section{Largest decreases in percentage of older workers in occupation, relative to older workers in all occupations}

Detailed Occ

6 Other managers

89 Shipping and receiving clerks

116 Other mechanics and repairers

127 Precision metal working occupations

136 Farm occupations, except managerial

150 Other machine operators, assorted materials

153 Production inspectors, testers, samplers, and weighers

161 Construction equipment operators

168 Other freight, stock, and material handlers

191 Other personal service occupations
Obs

2,549

244

234

241

576

298

161

370

303

\section{Largest increases in percentage of older workers in occupation, relative to older workers in all occupations}

Detailed Occ

\section{Occupation title}

Obs

4 Managers of medicine and health occupations

8 Other financial specialists

9 Management analysts

42 Lawyers and Judges

55 Health technologists and technicians

94 Cust. service reps, investigators and adjust., except insurance

100 Teacher assistants

135 Farm operators and managers

137 Gardeners and groundskeepers

158 Taxi cab drivers and chauffeurs
Change '92-'94

to $2010-12$

$-36 \%$

$-42 \%$

$-46 \%$

$-82 \%$

$-43 \%$

$-64 \%$

$-44 \%$

$-65 \%$

$-40 \%$

$-39 \%$

Change '92-'94

to $2010-12$

$242 \%$

$181 \%$

$282 \%$

$184 \%$

$129 \%$

$294 \%$

$133 \%$

$128 \%$

$126 \%$

$291 \%$
Change '92-'94 to

2006-08

$-34 \%$

$-47 \%$

$-54 \%$

$-75 \%$

$-26 \%$

$-51 \%$

$-50 \%$

$-60 \%$

$-36 \%$

$-46 \%$

Change '92-'94 to 2006-08

$168 \%$

$103 \%$

$256 \%$

$133 \%$

$164 \%$

$158 \%$

$121 \%$

$193 \%$

$101 \%$

$374 \%$ 
Table 2.1. Summary statistics from regressions of Pr(work FT past 62) and Pr(work FT past 65) on common covariates

\begin{tabular}{|c|c|c|c|c|c|c|}
\hline & Mean & 25 th \% & Median & 75th \% & St. Dev. & $\mathbf{N}$ \\
\hline Pr(work full-time after 62) & 51.74 & 10 & 50 & 90 & 38.02 & 3445 \\
\hline Pr(work full-time after 65) & 29.08 & 0 & 10 & 50 & 33.55 & 3427 \\
\hline Wave $(2=1994$ to $11=2012)$ & 5.84 & 3 & 5 & 9 & 3.11 & 3445 \\
\hline Good health or better & 0.89 & 1 & 1 & 1 & 0.32 & 3445 \\
\hline Has DB pension & 0.45 & 0 & 0 & 1 & 0.50 & 3445 \\
\hline In(total non-housing wealth) & 10.86 & 9.7 & 11.0 & 12.2 & 1.84 & 3445 \\
\hline Total non-housing wealth & $\$ 51,988$ & $\$ 16,065$ & $\$ 61,300$ & $\$ 196,000$ & & \\
\hline Educational category & 2.75 & 2 & 3 & 4 & 1.02 & 3445 \\
\hline Married & 0.70 & 0 & 1 & 1 & 0.46 & 3445 \\
\hline Female & 0.45 & 0 & 0 & 1 & 0.50 & 3445 \\
\hline In(labor earnings) & 10.5 & 10.1 & 10.5 & 11.0 & 0.87 & 3445 \\
\hline Labor earnings & $\$ 36,256$ & $\$ 24,000$ & $\$ 38,000$ & $\$ 60,000$ & & \\
\hline Usual retirement age & 63.03 & 62 & 65 & 65 & 3.41 & 1929 \\
\hline No usual retirement age $(0 / 1)$ & 0.29 & 0 & 0 & 1 & 0.45 & 2700 \\
\hline
\end{tabular}


Table 2.2. Regressions of $P 62$ and $P 65$ on common covariates

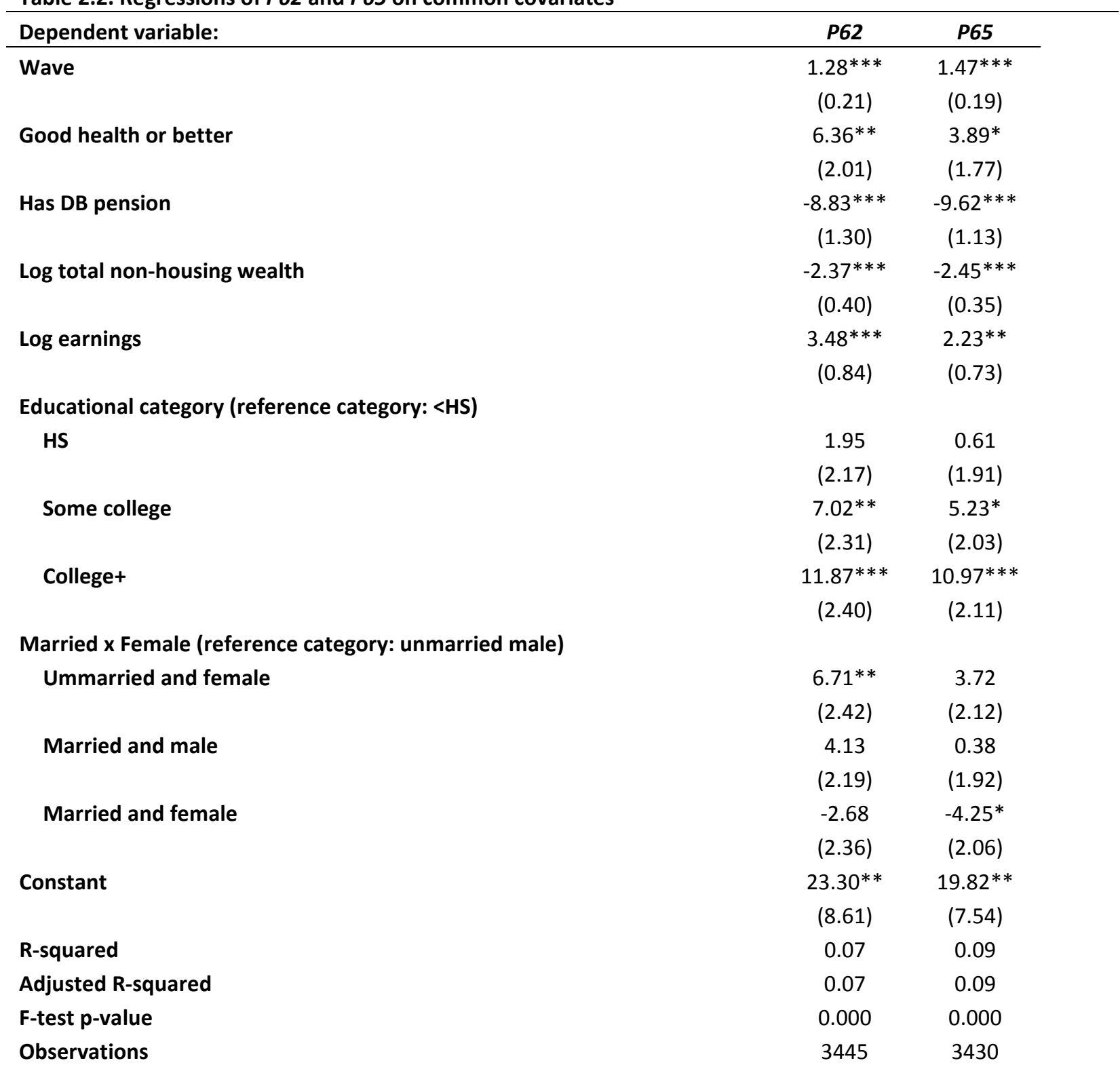

Note: Results from OLS regression with $P 62$ and $P 65$ (probability of full-time work past age 62 and 65 ) as dependent variables. Sample for this paper is all HRS participants who were working and not selfemployed at their first HRS interview, and aged 51-61 at that same interview. Sample in this table further restricts to a cross-section of all HRS respondents who were working at age 57/58. Base (excluded) categories are less than high school and unmarried males. Wave indicates HRS wave, 1=1992 through $11=2012$. Significance levels denoted as * for $p<0.05, * *$ for $p<0.01, * * *$ for $p<0.001$. 
Table 2.3. Public occupation category, current job

01. Managerial specialty ops.

02. Prof specialty opr/tech sup

03. Sales

04. Clerical/admin supp

05. Services: private hhld/clean/bldg

06. Services: protection

07. Services: Food prep

08. Health svc

09. Personal svc

10. Farming/forestry/fishing

11. Mechanics/repair

12. Construction trade/extractors

13. Precision production

14. Operators: machine

15. Operators: transport, etc

16. Operators: handlers, etc

17. Member of armed forces

Total

\begin{tabular}{|c|c|c|c|c|c|c|c|c|c|}
\hline \multirow[b]{2}{*}{ Obs. } & \multirow[b]{2}{*}{$\%$} & \multicolumn{3}{|c|}{ Pr (work past age 62) } & \multirow[b]{2}{*}{ St Dev } & \multicolumn{3}{|c|}{ Pr (work past age 65) } & \multirow[b]{2}{*}{ St Dev } \\
\hline & & Mean & Median & 75th \% & & Mean & Median & 75th \% & \\
\hline 487 & 17.0 & 55.9 & 50 & 95 & 37.5 & 31.1 & 20 & 50 & 34.1 \\
\hline 566 & 19.8 & 53.9 & 50 & 90 & 37.9 & 29.9 & 17.5 & 50 & 33.1 \\
\hline 206 & 7.2 & 56.3 & 55 & 90 & 35.2 & 33.0 & 20 & 50 & 34.0 \\
\hline 517 & 18.1 & 48.0 & 50 & 90 & 38.8 & 24.5 & 5 & 50 & 32.6 \\
\hline 13 & 0.5 & 33.5 & 1 & 70 & 39.8 & 20.0 & 0 & 50 & 30.0 \\
\hline 57 & 2.0 & 38.5 & 25 & 80 & 38.8 & 20.7 & 0 & 40 & 30.5 \\
\hline 49 & 1.7 & 48.4 & 50 & 100 & 40.6 & 26.6 & 10 & 50 & 32.6 \\
\hline 66 & 2.3 & 43.1 & 50 & 75 & 35.0 & 21.4 & 0 & 40 & 31.0 \\
\hline 122 & 4.3 & 48.6 & 50 & 90 & 40.0 & 29.7 & 10 & 50 & 36.3 \\
\hline 30 & 1.1 & 51.0 & 50 & 90 & 39.7 & 33.1 & 20 & 50 & 37.2 \\
\hline 131 & 4.6 & 53.1 & 50 & 100 & 39.2 & 27.4 & 5 & 50 & 35.8 \\
\hline 101 & 3.5 & 44.6 & 50 & 85 & 39.1 & 22.2 & 2 & 40 & 30.8 \\
\hline 111 & 3.9 & 45.6 & 50 & 90 & 41.1 & 20.2 & 2.5 & 30 & 30.6 \\
\hline 181 & 6.3 & 41.8 & 50 & 75 & 37.0 & 21.8 & 0 & 50 & 31.3 \\
\hline 148 & 5.2 & 46.8 & 50 & 92.5 & 42.0 & 24.5 & 2 & 50 & 31.4 \\
\hline 76 & 2.7 & 43.1 & 50 & 70 & 34.4 & 21.0 & 1.5 & 50 & 27.0 \\
\hline-- & -- & 25.0 & 25 & 50 & 35.4 & 5.0 & 5 & 10 & 7.1 \\
\hline 2,863 & 100 & 50.2 & 50 & 90 & 38.5 & 27.1 & 10 & 50 & 33.1 \\
\hline
\end{tabular}

Note: Included are those in the $P 62$ regressions on RAND public occupation categories (1980 codes), requiring respondents be at age 57 or 58 \& working. Frequencies with categories with 5 or fewer observations suppressed. 
2.4. Regressions of $P 62$ and $P 65$ on common covariates plus public occupation

\begin{tabular}{|c|c|c|c|c|}
\hline & \multicolumn{2}{|c|}{$\operatorname{Pr}($ work FT past 62) } & \multicolumn{2}{|c|}{$\operatorname{Pr}($ work FT past 65) } \\
\hline & coef. & se & coef. & se \\
\hline Wave & $1.68 * * *$ & 0.29 & $1.60 * * *$ & 0.25 \\
\hline Good health or better & $4.73^{*}$ & 2.31 & 2.91 & 1.98 \\
\hline Has DB pension & $-9.06 * * *$ & 1.45 & $-10.12 * * *$ & 1.24 \\
\hline Log total non-housing wealth & $-3.02 * * *$ & 0.46 & $-2.44 * * *$ & 0.39 \\
\hline Log earnings & $2.71 * *$ & 0.99 & $1.80 *$ & 0.84 \\
\hline \multicolumn{5}{|l|}{ Educational category (reference category: <HS) } \\
\hline HS & 0.4 & 2.44 & -0.49 & 2.1 \\
\hline Some college & 3.91 & 2.71 & 2.53 & 2.33 \\
\hline College+ & $7.97 * *$ & 3.02 & $8.13^{* *}$ & 2.6 \\
\hline \multicolumn{5}{|c|}{ Married x Female (reference category: unmarried male) } \\
\hline Married=0 \# Female=1 & 3.85 & 2.96 & 2.44 & 2.53 \\
\hline Married=1 \# Female=0 & 1.56 & 2.56 & -1.55 & 2.19 \\
\hline Married=1 \# Female=1 & -4.91 & 2.86 & $-5.49 *$ & 2.45 \\
\hline \multicolumn{5}{|c|}{ RAND Public Occupation (orig. codes) (excluded category: managerial specialty ops.) } \\
\hline 02. Prof specialty opr/tech sup & -2.21 & 2.35 & -1.98 & 2.01 \\
\hline 03. Sales & 0.06 & 3.17 & 1.59 & 2.72 \\
\hline 04. Clerical/admin supp & -5.03 & 2.56 & $-4.32 *$ & 2.19 \\
\hline 05. Services: private hhld/clean/bldg svc & $-22.18^{*}$ & 10.64 & -12.8 & 9.1 \\
\hline 06. Services: protection & $-17.42 * *$ & 5.29 & $-9.74 *$ & 4.52 \\
\hline 07. Services: Food prep & -9.21 & 5.77 & -6.75 & 4.93 \\
\hline 08. Health svc & $-13.17^{* *}$ & 5.05 & $-11.05^{*}$ & 4.32 \\
\hline 09. Personal svc & -6.72 & 4.08 & -1.47 & 3.52 \\
\hline 10. Farming/forestry/fishing & -5.92 & 7.35 & -0.35 & 6.28 \\
\hline 11. Mechanics/repair & -0.71 & 3.86 & -0.64 & 3.3 \\
\hline 12. Construction trade/extractors & $-9.99 *$ & 4.28 & -6.7 & 3.67 \\
\hline 13. Precision production & -7.07 & 4.07 & $-7.29 *$ & 3.49 \\
\hline 14. Operators: machine & $-10.75^{* *}$ & 3.51 & -5.6 & 3 \\
\hline 15. Operators: transport, etc & $-7.46^{*}$ & 3.79 & -4.54 & 3.24 \\
\hline 16. Operators: handlers, etc & $-12.20 *$ & 4.85 & $-9.58^{*}$ & 4.15 \\
\hline 17. Member of armed forces & -29.14 & 26.29 & -22.2 & 22.47 \\
\hline Constant & $47.69 * * *$ & 11.15 & $31.07 * *$ & 9.56 \\
\hline R-squared & \multicolumn{2}{|c|}{0.08} & \multicolumn{2}{|c|}{0.09} \\
\hline Adjusted R-squared & \multicolumn{2}{|c|}{0.07} & \multicolumn{2}{|c|}{0.08} \\
\hline F-test p-value & \multicolumn{2}{|c|}{0.000} & \multicolumn{2}{|c|}{0.000} \\
\hline Observations & \multicolumn{2}{|c|}{2863} & \multicolumn{2}{|c|}{2851} \\
\hline
\end{tabular}

Note: Results from OLS regression with P62/P65 (probability of full-time work past age 62/65) as dependent variable. Base (excluded) categories are less than high school, unmarried males, and managerial specialty ops. Wave indicates HRS wave, includes 1=1992 through 8=2006 only. Significance levels denoted as * for $p<0.05$, $* *$ for $\mathrm{p}<0.01, * * *$ for $\mathrm{p}<0.001$. 


\begin{tabular}{|c|c|c|c|c|c|c|c|c|c|c|c|}
\hline \multirow{2}{*}{\multicolumn{2}{|c|}{$\begin{array}{l}\text { Table 2.5. Detailed occupation plus } P 62 \text { and } P 65 \text { values } \\
\text { Occupation (custom categories) }\end{array}$}} & \multirow{3}{*}{$\begin{array}{c}\text { Obs. } \\
34\end{array}$} & \multirow{3}{*}{$\begin{array}{c}\% \\
1\end{array}$} & \multicolumn{4}{|c|}{ P62 } & \multicolumn{4}{|c|}{ P65 } \\
\hline & & & & Mean & Median & 75th \% & St Dev & Mean & Median & 75th \% & St Dev \\
\hline 1 & Financial managers & & & 68.7 & 72.5 & 100 & 30.9 & 43.8 & 35 & 80 & 36.7 \\
\hline 2 & Human resources, marketing, advertising, PR mgrs & 42 & 1.23 & 65.5 & 75 & 90 & 29.1 & 39.0 & 40 & 65 & 29.5 \\
\hline 3 & Managers in education and related fields & 45 & 1.32 & 49.4 & 50 & 80 & 35.6 & 26.1 & 20 & 40 & 26.9 \\
\hline 4 & Managers of medicine and health occupations & 17 & 0.5 & 54.7 & 80 & 90 & 43.1 & 33.8 & 10 & 75 & 38.8 \\
\hline 5 & Managers of properties and real estate & 11 & 0.32 & 77.2 & 100 & 100 & 36.8 & 52.0 & 50 & 80 & 34.8 \\
\hline 6 & Other managers & 289 & 8.48 & 57.0 & 65 & 95 & 37.9 & 32.4 & 20 & 50 & 34.6 \\
\hline 7 & Accountants and auditors & 25 & 0.73 & 61.4 & 75 & 80 & 34.7 & 28.4 & 25 & 50 & 31.9 \\
\hline 8 & Other financial specialists & 30 & 0.88 & 65.8 & 75 & 100 & 31.4 & 45.7 & 35 & 80 & 35.2 \\
\hline 9 & Management analysts & 11 & 0.32 & 55.9 & 90 & 90 & 44.3 & 41.4 & 20 & 80 & 40.5 \\
\hline 10 & Personnel, HR, training, and labor relations specialists & 18 & 0.53 & 54.4 & 50 & 100 & 37.2 & 21.5 & 5 & 25 & 33.5 \\
\hline 11 & Purchasing mgrs, agents, buyers; bus. \& promo agents & 26 & 0.76 & 46.0 & 50 & 90 & 38.3 & 22.5 & 10 & 40 & 30.0 \\
\hline 12 & Inspectors and compliance officers & 20 & 0.59 & 35.3 & 25 & 65 & 35.3 & 19.3 & 0 & 12.5 & 36.6 \\
\hline 13 & Management support occupations & 10 & 0.29 & 50.0 & 45 & 100 & 46.2 & 29.0 & 10 & 50 & 37.0 \\
\hline 14 & Civil engineers & 9 & 0.26 & 49.4 & 50 & 85 & 41.6 & 22.4 & 20 & 30 & 23.1 \\
\hline 15 & Electrical engineers & 13 & 0.38 & 60.8 & 75 & 90 & 37.8 & 40.0 & 30 & 50 & 32.6 \\
\hline 16 & Industrial engineers & 21 & 0.62 & 73.8 & 80 & 100 & 30.0 & 49.8 & 50 & 80 & 32.6 \\
\hline 17 & Mechanical engineers & -- & -- & 86.0 & 90 & 100 & 20.7 & 58.0 & 75 & 90 & 43.4 \\
\hline 18 & Other engineers, architects, surveyors and mapping scientists & 18 & 0.53 & 74.7 & 85 & 100 & 29.5 & 38.1 & 40 & 75 & 32.7 \\
\hline 19 & Mathematical and computer scientists & 29 & 0.85 & 46.3 & 50 & 80 & 35.7 & 22.9 & 20 & 40 & 25.4 \\
\hline 20 & Physical scientists & 7 & 0.21 & 27.1 & 25 & 40 & 27.4 & 14.3 & 10 & 10 & 25.1 \\
\hline 21 & Life scientists & -- & -- & 78.8 & 82.5 & 95 & 21.7 & 71.3 & 72.5 & 82.5 & 16.5 \\
\hline 22 & Physicians & 6 & 0.18 & 86.7 & 90 & 95 & 9.8 & 64.2 & 80 & 90 & 35.3 \\
\hline 23 & Dentists & -- & -- & 75.0 & 75 & 100 & 35.4 & 75.0 & 75 & 100 & 35.4 \\
\hline 24 & Other health and therapy occupations & 12 & 0.35 & 43.3 & 50 & 70 & 31.9 & 28.3 & 12.5 & 52.5 & 35.9 \\
\hline 25 & Registered nurses & 60 & 1.76 & 56.5 & 67.5 & 90 & 39.0 & 40.9 & 40 & 75 & 36.0 \\
\hline 26 & Pharmacist & -- & -- & 30.0 & 20 & 70 & 36.1 & 11.7 & 10 & 25 & 12.6 \\
\hline 27 & Therapists & 12 & 0.35 & 46.3 & 45 & 70 & 35.0 & 26.7 & 20 & 35 & 32.6 \\
\hline 28 & Dietitians, nutritionists and physicians assistants & -- & -- & 72.0 & 90 & 100 & 42.1 & 66.0 & 70 & 100 & 37.8 \\
\hline 29 & Postsecondary teachers & 51 & 1.5 & 68.7 & 85 & 90 & 34.0 & 36.7 & 35 & 60 & 31.7 \\
\hline 30 & Kindergarten and earlier school teachers & 12 & 0.35 & 40.1 & 32.5 & 70 & 34.9 & 20.2 & 0.5 & 35 & 32.4 \\
\hline 31 & Primary school teachers & 70 & 2.05 & 38.8 & 35 & 75 & 36.9 & 16.9 & 0 & 25 & 26.3 \\
\hline 32 & Secondary school teachers & 65 & 1.91 & 43.9 & 50 & 80 & 35.9 & 21.7 & 10 & 30 & 29.8 \\
\hline 33 & Special education teachers & 10 & 0.29 & 43.5 & 37.5 & 80 & 43.5 & 25.5 & 2.5 & 40 & 41.1 \\
\hline 34 & Teachers, nec & 12 & 0.35 & 61.7 & 75 & 97.5 & 37.0 & 32.9 & 20 & 50 & 30.6 \\
\hline
\end{tabular}


Table 2.5. Detailed occupation plus $P 62$ and $P 65$ values

\begin{tabular}{|c|c|c|c|c|c|c|c|c|c|c|c|}
\hline \multicolumn{2}{|c|}{ Table 2.3. Detalled occupation plus roz ana ros values } & \multirow{3}{*}{$\begin{array}{c}\text { Obs. } \\
16\end{array}$} & \multirow{3}{*}{$\begin{array}{c}\% \\
0.47\end{array}$} & \multicolumn{4}{|c|}{102} & \multicolumn{4}{|c|}{ כסק } \\
\hline \multicolumn{2}{|r|}{ Occupation (custom categories) } & & & Mean & Median & 75th \% & St Dev & Mean & Median & 75th \% & St Dev \\
\hline 35 & Vocational and educational counselors & & & 56.5 & 55 & 94.5 & 37.3 & 21.6 & 3 & 50 & 29.3 \\
\hline 36 & Librarians, Archivists, and Curators & 12 & 0.35 & 55.0 & 72.5 & 90 & 41.4 & 34.6 & 20 & 72.5 & 37.0 \\
\hline 37 & Psychologists & 9 & 0.26 & 55.6 & 75 & 80 & 38.5 & 27.8 & 20 & 50 & 30.0 \\
\hline 38 & Other social scientists and urban planners & 6 & 0.18 & 63.3 & 55 & 80 & 22.5 & 36.7 & 40 & 50 & 16.3 \\
\hline 39 & Social workers & 33 & 0.97 & 62.7 & 80 & 90 & 35.5 & 36.1 & 25 & 65 & 36.9 \\
\hline 40 & Recreational workers & -- & -- & 66.7 & 100 & 100 & 57.7 & 33.3 & 0 & 100 & 57.7 \\
\hline 41 & Clergy and religious workers & 22 & 0.65 & 73.4 & 90 & 100 & 32.3 & 45.7 & 50 & 90 & 40.1 \\
\hline 42 & Lawyers and Judges & 12 & 0.35 & 84.2 & 90 & 100 & 17.9 & 61.3 & 62.5 & 95 & 34.9 \\
\hline 43 & Writers, authors, technical writers & -- & -- & 65.0 & 65 & 100 & 49.5 & 22.5 & 22.5 & 25 & 3.5 \\
\hline 44 & Designers & -- & -- & 73.3 & 72.5 & 86.5 & 19.7 & 47.5 & 45 & 70 & 33.0 \\
\hline 45 & Musician or composer & -- & -- & -- & -- & -- & -- & -- & -- & -- & -- \\
\hline 46 & Actors, directors, producers & -- & -- & -- & -- & -- & -- & -- & -- & -- & -- \\
\hline 47 & Art makers: painters, sculptors, craft-artists, \& print-makers & -- & -- & 63.3 & 90 & 95 & 50.6 & 60.0 & 90 & 90 & 52.0 \\
\hline 48 & Photographers & -- & -- & -- & -- & -- & -- & -- & -- & -- & -- \\
\hline 49 & Art/entertainment performers and related & -- & -- & 80.0 & 90 & 100 & 26.5 & 31.7 & 25 & 50 & 16.1 \\
\hline 50 & Editors and reporters & -- & -- & 76.7 & 80 & 90 & 15.3 & 46.7 & 50 & 50 & 5.8 \\
\hline 51 & Athletes, sports instructors, officials and announcers & -- & -- & -- & -- & -- & -- & -- & -- & -- & -- \\
\hline 52 & Clinical laboratory technologies and techs, dental hygenists & 13 & 0.38 & 48.5 & 50 & 75 & 32.4 & 19.6 & 0 & 30 & 27.6 \\
\hline 53 & Radiologic tech specialists & -- & -- & 40.0 & 20 & 100 & 52.9 & 31.7 & 5 & 90 & 50.6 \\
\hline 54 & Licensed practical nurses & 19 & 0.56 & 55.0 & 50 & 100 & 40.4 & 24.2 & 10 & 50 & 34.7 \\
\hline 55 & Health technologists and technicians, nec & 15 & 0.44 & 57.7 & 75 & 100 & 41.6 & 38.3 & 25 & 90 & 39.9 \\
\hline 56 & Engineering, surveyor and mapping technicians & 20 & 0.59 & 46.5 & 37.5 & 90 & 40.0 & 29.5 & 0 & 75 & 40.8 \\
\hline 57 & Drafters & -- & -- & 75.0 & 80 & 90 & 25.2 & 47.5 & 40 & 65 & 29.9 \\
\hline 58 & Science technicians & 12 & 0.35 & 58.1 & 75 & 85 & 36.8 & 38.3 & 35 & 65 & 34.1 \\
\hline 59 & Airplane pilots and navigators, air traffic controllers & -- & -- & 49.0 & 75 & 80 & 45.1 & 25.0 & 0 & 50 & 35.4 \\
\hline 60 & Computer programmers, support specialists \& administrators & 25 & 0.73 & 56.4 & 70 & 85 & 34.7 & 38.5 & 30 & 72.5 & 35.8 \\
\hline 61 & Technicians, nec & 14 & 0.41 & 37.9 & 15 & 75 & 42.5 & 20.8 & 3 & 25 & 33.3 \\
\hline 62 & Supervisors and proprietors of sales jobs & 86 & 2.52 & 59.2 & 75 & 100 & 37.0 & 39.1 & 32.5 & 75 & 36.3 \\
\hline 63 & Insurance sales occupations & 14 & 0.41 & 57.9 & 80 & 100 & 44.0 & 37.9 & 35 & 75 & 38.2 \\
\hline 64 & Real estate sales occupations & 8 & 0.23 & 60.6 & 80 & 80 & 32.6 & 48.8 & 50 & 80 & 30.3 \\
\hline 65 & Financial services sales occupations & 7 & 0.21 & 82.9 & 100 & 100 & 26.3 & 64.3 & 90 & 95 & 44.6 \\
\hline 66 & Advertising and related sales jobs & -- & -- & 15.0 & 20 & 25 & 13.2 & 5.0 & 5 & 10 & 5.0 \\
\hline 67 & Cashiers & 25 & 0.73 & 40.0 & 40 & 70 & 35.8 & 17.8 & 0 & 20 & 23.6 \\
\hline 68 & Door-to-door sales, street sales, and news vendors & -- & -- & 73.8 & 72.5 & 97.5 & 27.5 & 57.5 & 50 & 75 & 29.9 \\
\hline
\end{tabular}


Table 2.5. Detailed occupation plus $P 62$ and $P 65$ values

P62

P65

\begin{tabular}{|c|c|c|c|c|c|c|c|c|c|c|c|}
\hline \multicolumn{2}{|c|}{ Occupation (custom categories) } & \multirow{2}{*}{$\begin{array}{c}\text { Obs. } \\
104\end{array}$} & \multirow{2}{*}{$\begin{array}{c}\% \\
3.05\end{array}$} & \multirow{2}{*}{$\frac{\text { Mean }}{58.3}$} & \multirow{2}{*}{$\frac{\text { Median }}{67.5}$} & \multirow{2}{*}{$\begin{array}{c}\text { 75th \% } \\
92.5\end{array}$} & \multirow{2}{*}{$\frac{\text { St Dev }}{35.9}$} & \multirow{2}{*}{$\frac{\text { Mean }}{33.4}$} & \multirow{2}{*}{$\frac{\text { Median }}{25}$} & \multirow{2}{*}{$\begin{array}{c}\text { 75th \% } \\
50\end{array}$} & \multirow{2}{*}{$\frac{\text { St Dev }}{32.7}$} \\
\hline 69 & Other sales and sales related & & & & & & & & & & \\
\hline 70 & Office supervisors & 71 & 2.08 & 51.8 & 50 & 80 & 36.0 & 27.5 & 10 & 50 & 31.3 \\
\hline 71 & Computer and peripheral equipment operators & 14 & 0.41 & 51.8 & 50 & 75 & 35.3 & 20.0 & 10 & 25 & 27.7 \\
\hline 72 & Secretaries, Stenographers, and Typists & 132 & 3.87 & 49.8 & 50 & 90 & 39.4 & 27.6 & 10 & 50 & 34.0 \\
\hline 73 & Interviewers, enumerators, and surveyors & -- & -- & 62.0 & 50 & 100 & 35.8 & 47.0 & 50 & 50 & 36.0 \\
\hline 74 & Transportation ticket and reservation agents & -- & -- & 30.0 & 10 & 80 & 43.6 & 27.3 & 2 & 80 & 45.6 \\
\hline 75 & Information clerks, nec & 28 & 0.82 & 58.5 & 75 & 99.5 & 40.0 & 26.6 & 10 & 50 & 33.7 \\
\hline 76 & Correspondence and order clerks & -- & -- & 62.0 & 80 & 100 & 44.9 & 27.0 & 10 & 50 & 33.8 \\
\hline 77 & Human resources clerks, except payroll and timekeeping & -- & -- & 58.3 & 75 & 100 & 52.0 & 11.7 & 10 & 25 & 12.6 \\
\hline 78 & Library assistants & 8 & 0.23 & 53.8 & 62.5 & 87.5 & 39.5 & 39.4 & 17.5 & 85 & 43.0 \\
\hline 79 & File clerks & -- & -- & 62.5 & 60 & 87.5 & 31.2 & 51.3 & 42.5 & 75 & 34.7 \\
\hline 80 & Records clerks & -- & -- & 51.7 & 45 & 100 & 45.4 & 43.3 & 30 & 100 & 51.3 \\
\hline 81 & Bookkeepers and accounting and auditing clerks & 66 & 1.94 & 50.4 & 50 & 80 & 35.6 & 28.7 & 20 & 50 & 33.1 \\
\hline 82 & Other financial records processing occupations & 22 & 0.65 & 59.8 & 50 & 100 & 35.8 & 34.5 & 20 & 75 & 37.1 \\
\hline 83 & Duplicating, mail, and other office machine operators & 6 & 0.18 & 29.2 & 37.5 & 50 & 24.6 & 14.2 & 5 & 25 & 20.1 \\
\hline 84 & Postal clerks, excluding mail carriers & 13 & 0.38 & 68.1 & 100 & 100 & 41.3 & 29.2 & 5 & 50 & 34.8 \\
\hline 85 & Mail carriers for postal service & 13 & 0.38 & 38.8 & 50 & 60 & 33.8 & 18.5 & 10 & 30 & 20.7 \\
\hline 86 & Mail clerks, outside of post office & -- & -- & 48.0 & 50 & 75 & 41.3 & 11.0 & 0 & 5 & 21.9 \\
\hline 87 & Messengers & 6 & 0.18 & 67.5 & 90 & 100 & 43.6 & 48.3 & 50 & 90 & 42.6 \\
\hline 88 & Dispatchers & 13 & 0.38 & 33.5 & 20 & 50 & 39.5 & 11.9 & 0 & 5 & 28.1 \\
\hline 89 & Shipping and receiving clerks & 20 & 0.59 & 24.8 & 5 & 50 & 34.2 & 11.1 & 0 & 10 & 25.4 \\
\hline 90 & Stock and inventory clerks & 33 & 0.97 & 48.8 & 50 & 80 & 35.7 & 27.0 & 10 & 50 & 35.0 \\
\hline 91 & Weighers, measurers, checkers, meter readers & -- & -- & 60.0 & 50 & 100 & 41.8 & 28.0 & 20 & 50 & 31.1 \\
\hline 92 & Material recording, sched., prod., planning, \& exped. clerks & 15 & 0.44 & 41.5 & 30 & 90 & 42.9 & 9.6 & 1 & 10 & 16.2 \\
\hline 93 & Insurance adjusters, examiners, and investigators & 12 & 0.35 & 55.4 & 62.5 & 95 & 40.1 & 28.3 & 10 & 50 & 33.5 \\
\hline 94 & Customer svc reps, investigators \& adjusters, exc. insurance & 28 & 0.82 & 54.8 & 55 & 90 & 36.7 & 39.0 & 25 & 72.5 & 36.0 \\
\hline 95 & Eligibility clerks for government programs; social welfare & 8 & 0.23 & 57.5 & 65 & 87.5 & 35.9 & 38.1 & 25 & 77.5 & 43.9 \\
\hline 96 & Bill and account collectors & 9 & 0.26 & 81.1 & 100 & 100 & 34.8 & 54.4 & 50 & 100 & 45.3 \\
\hline 97 & General office clerks & 23 & 0.67 & 42.8 & 35 & 100 & 40.6 & 29.6 & 10 & 50 & 37.3 \\
\hline 98 & Bank tellers & 15 & 0.44 & 44.7 & 50 & 90 & 43.2 & 14.7 & 10 & 30 & 18.1 \\
\hline 99 & Data entry keyers & 8 & 0.23 & 35.0 & 25 & 65 & 37.5 & 8.8 & 0 & 5 & 21.0 \\
\hline 100 & Teacher assistants & 20 & 0.59 & 47.3 & 50 & 75 & 37.4 & 21.5 & 2.5 & 40 & 30.4 \\
\hline 101 & Other administrative support occupations & 23 & 0.67 & 59.1 & 70 & 100 & 35.6 & 29.6 & 20 & 50 & 28.3 \\
\hline 102 & Supervisors of mechanics and repairers & 27 & 0.79 & 54.1 & 50 & 80 & 35.8 & 34.8 & 20 & 50 & 36.9 \\
\hline 103 & Automobile mechanics & 7 & 0.21 & 72.9 & 100 & 100 & 41.1 & 47.9 & 75 & 80 & 45.4 \\
\hline
\end{tabular}


Table 2.5. Detailed occupation plus $P 62$ and $P 65$ values P62 P65

\begin{tabular}{|c|c|c|c|c|c|c|c|c|c|c|c|}
\hline \multicolumn{2}{|c|}{ Occupation (custom categories) } & \multirow{2}{*}{$\begin{array}{c}\text { Obs. } \\
8\end{array}$} & \multirow{2}{*}{$\begin{array}{c}\% \\
0.23\end{array}$} & \multirow{2}{*}{$\frac{\text { Mean }}{61.9}$} & \multirow{2}{*}{$\frac{\text { Median }}{77.5}$} & \multirow{2}{*}{$\frac{\text { 75th \% }}{100}$} & \multirow{2}{*}{$\frac{\text { St Dev }}{42.1}$} & \multirow{2}{*}{$\frac{\text { Mean }}{28.8}$} & \multirow{2}{*}{$\frac{\text { Median }}{15}$} & \multirow{2}{*}{$\begin{array}{c}\text { 75th \% } \\
50\end{array}$} & \multirow{2}{*}{$\frac{\text { St Dev }}{36.4}$} \\
\hline 104 & Bus, truck, and stationary engine mechanics & & & & & & & & & & \\
\hline 105 & Aircraft mechanics & -- & -- & 50.0 & 60 & 90 & 45.8 & 23.3 & 10 & 60 & 32.1 \\
\hline 106 & Auto body repairers & -- & -- & -- & -- & -- & -- & -- & -- & -- & -- \\
\hline 107 & Heavy equipment and farm equipment mechanics & 6 & 0.18 & 48.7 & 50 & 90 & 45.0 & 9.5 & 1 & 5 & 19.9 \\
\hline 108 & Industrial machinery repairers & 27 & 0.79 & 49.9 & 50 & 90 & 40.4 & 24.1 & 0 & 40 & 38.0 \\
\hline 109 & Other machinery maintenance and repairers & -- & -- & 79.0 & 80 & 90 & 18.8 & 31.0 & 0 & 75 & 42.5 \\
\hline 110 & Repairers of industrial electrical equipment & -- & -- & 50.0 & 50 & 80 & 30.0 & 33.3 & 20 & 60 & 23.1 \\
\hline 111 & Repairers of data processing equip. or other office machines & -- & -- & 51.0 & 51 & 100 & 69.3 & 15.0 & 15 & 30 & 21.2 \\
\hline 112 & Telecom and line installers and repairers & 14 & 0.41 & 37.8 & 17.5 & 99 & 44.8 & 26.7 & 0 & 50 & 37.1 \\
\hline 113 & Heating, air conditioning, and refigeration mechanics & 7 & 0.21 & 35.7 & 30 & 80 & 39.5 & 20.7 & 5 & 50 & 31.7 \\
\hline 114 & Other electronic or electrical equipment repairers & 6 & 0.18 & 48.3 & 50 & 90 & 42.6 & 14.2 & 5 & 25 & 20.1 \\
\hline 115 & Precision makers, repairers, smiths; other & -- & -- & 44.0 & 50 & 50 & 37.8 & 22.0 & 25 & 25 & 18.9 \\
\hline 116 & Other mechanics and repairers & 27 & 0.79 & 53.7 & 50 & 90 & 36.5 & 32.3 & 20 & 50 & 39.6 \\
\hline 117 & Supervisors of construction work & 34 & 1 & 58.2 & 55 & 90 & 33.6 & 31.1 & 30 & 50 & 31.5 \\
\hline 118 & Masons, tilers, and carpet installers & -- & -- & 26.7 & 30 & 50 & 25.2 & 26.7 & 30 & 50 & 25.2 \\
\hline 119 & Carpenters & 13 & 0.38 & 37.3 & 40 & 50 & 39.1 & 23.1 & 0 & 50 & 31.5 \\
\hline 120 & Drywall installers & -- & -- & -- & -- & -- & -- & -- & -- & -- & -- \\
\hline 121 & Electricians, electric power installers and repairers & 17 & 0.5 & 49.7 & 70 & 90 & 44.1 & 19.1 & 0 & 20 & 34.7 \\
\hline 122 & Painters, construction and maintenance & 10 & 0.29 & 57.2 & 50 & 100 & 40.8 & 31.7 & 17.5 & 50 & 36.6 \\
\hline 123 & Plumbers, pipe fitters, and steamfitters & 16 & 0.47 & 40.6 & 30 & 80 & 39.2 & 17.5 & 0 & 25 & 30.4 \\
\hline 124 & Other construction trades & 17 & 0.5 & 45.0 & 40 & 80 & 40.9 & 23.5 & 0 & 50 & 30.1 \\
\hline 126 & Production supervisors or foremen & 48 & 1.41 & 48.4 & 45 & 80 & 37.9 & 23.3 & 5 & 50 & 32.7 \\
\hline 127 & Precision metal working occupations & 25 & 0.73 & 41.4 & 40 & 90 & 41.1 & 14.4 & 10 & 10 & 26.6 \\
\hline 128 & Precision woodworking occupations & -- & -- & -- & -- & -- & -- & -- & -- & -- & -- \\
\hline 129 & Precision textile, apparel, and furnishings machine workers & -- & -- & 52.5 & 55 & 100 & 55.0 & 2.5 & 0 & 5 & 5.0 \\
\hline 130 & Optical goods workers, dental lab. \& med appliance techs & 7 & 0.21 & 78.6 & 80 & 100 & 24.8 & 40.7 & 30 & 80 & 30.6 \\
\hline 131 & Other precision workers, assorted materials & 20 & 0.59 & 61.5 & 50 & 90 & 30.8 & 26.5 & 17.5 & 50 & 28.2 \\
\hline 132 & Butchers and meat cutters & 8 & 0.23 & 45.6 & 50 & 82.5 & 41.5 & 25.0 & 5 & 50 & 34.2 \\
\hline 133 & Bakers and batch food makers & -- & -- & 70.0 & 85 & 100 & 42.4 & 47.5 & 40 & 85 & 45.0 \\
\hline 134 & Plant and system operators, adjusters and calibrators & 16 & 0.47 & 41.6 & 37.5 & 67.5 & 37.3 & 17.5 & 5 & 25 & 27.9 \\
\hline 135 & Farm operators and managers & -- & -- & 76.7 & 80 & 80 & 5.8 & 55.0 & 50 & 75 & 18.0 \\
\hline 136 & Farm occupations, except managerial & 17 & 0.5 & 51.2 & 50 & 100 & 44.6 & 35.0 & 15 & 77.5 & 41.7 \\
\hline 137 & Gardeners and groundskeepers & 18 & 0.53 & 52.2 & 50 & 80 & 36.5 & 26.9 & 20 & 50 & 27.9 \\
\hline 138 & Other agricultural occupations & -- & -- & 45.0 & 40 & 65 & 26.5 & 67.5 & 75 & 100 & 39.5 \\
\hline 139 & Timber, logging, and forestry workers & -- & -- & 75.0 & 75 & 100 & 35.4 & 10.0 & 10 & 20 & 14.1 \\
\hline
\end{tabular}


Table 2.5. Detailed occupation plus $P 62$ and $P 65$ values

P62

P65

\begin{tabular}{|c|c|c|c|c|c|c|c|c|c|c|c|}
\hline \multicolumn{2}{|c|}{ Occupation (custom categories) } & \multirow{2}{*}{$\frac{\text { Obs. }}{18}$} & \multirow{2}{*}{$\frac{\%}{0.53}$} & \multirow{2}{*}{$\frac{\text { Mean }}{39.8}$} & \multirow{2}{*}{$\frac{\text { Median }}{35}$} & \multirow{2}{*}{$\begin{array}{c}\text { 75th \% } \\
60\end{array}$} & \multirow{2}{*}{$\frac{\text { St Dev }}{36.4}$} & \multirow{2}{*}{$\frac{\text { Mean }}{23.3}$} & \multirow{2}{*}{$\frac{\text { Median }}{0}$} & \multirow{2}{*}{$\frac{\text { 75th \% }}{50}$} & \multirow{2}{*}{$\frac{\text { St Dev }}{37.3}$} \\
\hline 141 & Metal working and plastic working machine operators & & & & & & & & & & \\
\hline 142 & Metal and plastic processing machine operators & -- & -- & -- & -- & -- & -- & 15.0 & 15 & 25 & 14.1 \\
\hline 143 & Woodworking machine operators & -- & -- & 60.0 & 50 & 75 & 27.1 & 42.5 & 30 & 70 & 40.3 \\
\hline 144 & Textile sewing machine operators & 7 & 0.21 & 28.6 & 20 & 75 & 35.0 & 16.4 & 0 & 25 & 29.5 \\
\hline 145 & Laundry workers & -- & -- & 30.0 & 0 & 90 & 52.0 & 33.3 & 0 & 100 & 57.7 \\
\hline 146 & Other textile, apparel, and furnishings machine operators & -- & -- & 78.3 & 85 & 100 & 25.7 & 0.0 & 0 & 0 & 0.0 \\
\hline 147 & Packers, fillers, and wrappers & -- & -- & 38.0 & 50 & 60 & 36.3 & 36.0 & 50 & 50 & 35.1 \\
\hline 148 & Painting machine operators & -- & -- & 40.0 & 10 & 100 & 52.0 & 30.0 & 0 & 90 & 52.0 \\
\hline 149 & Slicing and cutting machine operators & -- & -- & 66.7 & 50 & 100 & 28.9 & 48.3 & 60 & 75 & 34.0 \\
\hline 150 & Other machine operators, assorted materials & 60 & 1.76 & 38.8 & 35 & 60 & 36.9 & 20.2 & 1 & 27.5 & 30.8 \\
\hline 151 & Welders, metal cutters, solderers & 20 & 0.59 & 45.0 & 50 & 77.5 & 38.6 & 24.5 & 10 & 50 & 29.4 \\
\hline 152 & Assemblers and fabricators & 34 & 1 & 39.7 & 40 & 80 & 40.0 & 24.9 & 0 & 50 & 35.7 \\
\hline 153 & Production inspectors, testers, samplers, and weighers & 28 & 0.82 & 40.4 & 50 & 72.5 & 35.9 & 17.7 & 0 & 25 & 27.3 \\
\hline 154 & Supervisors of motor vehicle transportation & 16 & 0.47 & 62.8 & 62.5 & 100 & 34.3 & 29.7 & 22.5 & 50 & 29.7 \\
\hline 155 & Truck, delivery, tractor drivers and parking lot attendants & 82 & 2.4 & 51.8 & 50 & 90 & 40.1 & 31.3 & 20 & 50 & 30.8 \\
\hline 156 & Industrial truck and tractor operators & 24 & 0.7 & 44.2 & 45 & 85 & 40.2 & 17.3 & 0 & 22.5 & 30.6 \\
\hline 157 & Bus drivers & 23 & 0.67 & 46.5 & 50 & 100 & 43.3 & 29.2 & 20 & 50 & 34.8 \\
\hline 158 & Taxi cab drivers and chauffeurs & 8 & 0.23 & 36.3 & 30 & 65 & 39.6 & 19.4 & 0 & 40 & 33.0 \\
\hline 159 & Rail transportation occupations & 7 & 0.21 & 33.7 & 5 & 80 & 42.8 & 14.3 & 0 & 20 & 29.9 \\
\hline 160 & Water transportation occupations & -- & -- & -- & -- & -- & -- & -- & -- & -- & -- \\
\hline 161 & Construction equipment operators & 17 & 0.5 & 30.9 & 0 & 50 & 42.9 & 11.1 & 0 & 0 & 25.9 \\
\hline 162 & Crane, derrick, winch, and hoist operators & -- & -- & 33.3 & 0 & 100 & 57.7 & 16.7 & 0 & 50 & 28.9 \\
\hline 163 & Misc material moving occupations & 6 & 0.18 & 68.3 & 80 & 100 & 38.2 & 41.7 & 50 & 50 & 37.6 \\
\hline 164 & Construction helpers and laborers, surveyor helpers & 19 & 0.56 & 31.1 & 10 & 60 & 36.1 & 14.3 & 0 & 20 & 28.1 \\
\hline 165 & Production helpers & -- & -- & -- & -- & -- & -- & -- & -- & -- & -- \\
\hline 166 & Vehicle washers and equipment cleaners & -- & -- & 42.0 & 60 & 70 & 39.0 & 14.0 & 0 & 20 & 21.9 \\
\hline 167 & Packers and packagers by hand & 7 & 0.21 & 38.6 & 30 & 80 & 39.8 & 31.4 & 10 & 70 & 40.2 \\
\hline 168 & Other freight, stock, and material handlers & 38 & 1.11 & 41.6 & 50 & 50 & 31.4 & 22.4 & 10 & 40 & 28.2 \\
\hline 169 & Supervisors in protective services & 25 & 0.73 & 48.6 & 60 & 90 & 42.0 & 24.6 & 5 & 50 & 34.2 \\
\hline 170 & Fire fighting, prevention, and inspection & -- & -- & 75.0 & 75 & 100 & 35.4 & 50.0 & 50 & 100 & 70.7 \\
\hline 171 & Police, detectives, and private investigators & 17 & 0.5 & 33.2 & 10 & 60 & 39.0 & 22.1 & 0 & 50 & 31.1 \\
\hline 172 & Other law enforce: sheriffs, bailiffs, correctional officers & 10 & 0.29 & 45.5 & 50 & 80 & 37.9 & 18.2 & 1 & 40 & 28.5 \\
\hline 173 & Guards, watchmen, doorkeepers & 19 & 0.56 & 41.6 & 30 & 90 & 37.9 & 19.2 & 10 & 40 & 21.9 \\
\hline 174 & Other protective services & -- & -- & -- & -- & -- & -- & -- & -- & -- & -- \\
\hline 175 & Private household occupations & 28 & 0.82 & 46.4 & 50 & 85 & 41.1 & 28.2 & 0 & 50 & 36.5 \\
\hline
\end{tabular}


Table 2.5. Detailed occupation plus $P 62$ and $P 65$ values

P62

P65

\begin{tabular}{|c|c|c|c|c|c|c|c|c|c|c|c|}
\hline \multicolumn{2}{|c|}{ Occupation (custom categories) } & \multirow{2}{*}{$\begin{array}{c}\text { Obs. } \\
--\end{array}$} & \multirow{2}{*}{$\begin{array}{l}\% \\
--\end{array}$} & \multirow{2}{*}{$\begin{array}{c}\text { Mean } \\
20.0\end{array}$} & \multirow{2}{*}{$\frac{\text { Median }}{20}$} & \multirow{2}{*}{$\begin{array}{c}\text { 75th \% } \\
40\end{array}$} & \multirow{2}{*}{$\begin{array}{c}\text { St Dev } \\
28.3\end{array}$} & \multirow{2}{*}{$\begin{array}{c}\text { Mean } \\
15.0\end{array}$} & \multirow{2}{*}{$\frac{\text { Median }}{15}$} & \multirow{2}{*}{$\begin{array}{c}\text { 75th \% } \\
30\end{array}$} & \multirow{2}{*}{$\begin{array}{c}\text { St Dev } \\
21.2\end{array}$} \\
\hline 176 & Bartenders & & & & & & & & & & \\
\hline 177 & Waiter/waitress, food counter and fountain workers & 8 & 0.23 & 59.4 & 62.5 & 100 & 42.1 & 55.6 & 60 & 87.5 & 39.2 \\
\hline 178 & Chefs, head cooks and food supervisors & 13 & 0.38 & 53.5 & 50 & 90 & 41.5 & 40.0 & 50 & 60 & 39.4 \\
\hline 179 & Other cooks & 22 & 0.65 & 48.9 & 45 & 100 & 41.5 & 23.4 & 2.5 & 50 & 30.8 \\
\hline 180 & Kitchen workers & -- & -- & 42.5 & 50 & 60 & 29.9 & 27.5 & 25 & 45 & 25.0 \\
\hline 181 & Waiter's assistant & -- & -- & 56.3 & 52.5 & 90 & 39.9 & 17.5 & 10 & 35 & 23.6 \\
\hline 182 & Misc food prep workers & 6 & 0.18 & 45.0 & 55 & 60 & 38.9 & 15.8 & 2.5 & 40 & 22.9 \\
\hline 183 & Janitors & 69 & 2.02 & 44.9 & 50 & 90 & 40.4 & 22.6 & 0 & 50 & 30.8 \\
\hline 184 & Other cleaning \& bldg service occupations, exc households & 14 & 0.41 & 49.3 & 50 & 90 & 42.3 & 40.4 & 20 & 90 & 43.3 \\
\hline 185 & Dental assistants & 9 & 0.26 & 45.0 & 50 & 75 & 32.1 & 15.6 & 10 & 20 & 18.8 \\
\hline 186 & Health aides, except nursing & 16 & 0.47 & 40.0 & 35 & 77.5 & 37.0 & 15.0 & 0 & 32.5 & 20.9 \\
\hline 187 & Nursing aides, orderlies, and attendants & 50 & 1.47 & 44.9 & 50 & 80 & 35.8 & 18.8 & 0 & 25 & 29.4 \\
\hline 188 & Barbers, hairdressers and cosmetologists & -- & -- & 50.0 & 50 & 100 & 50.0 & 50.0 & 50 & 100 & 50.0 \\
\hline 189 & Recreation facility attendants & -- & -- & 40.0 & 30 & 75 & 45.5 & 27.5 & 5 & 55 & 48.6 \\
\hline 190 & Child care workers & 17 & 0.5 & 41.8 & 50 & 75 & 38.9 & 26.5 & 0 & 50 & 35.2 \\
\hline 191 & Other personal service occupations & 26 & 0.76 & 55.2 & 77.5 & 100 & 43.6 & 36.5 & 32.5 & 75 & 38.3 \\
\hline \multirow[t]{2}{*}{192} & Military & -- & -- & 30.0 & 30 & 60 & 42.4 & 25.0 & 25 & 50 & 35.4 \\
\hline & Overall & 3,410 & 100 & 51.8 & 50 & 90 & 38.0 & 29.1 & 10 & 50 & 33.5 \\
\hline
\end{tabular}

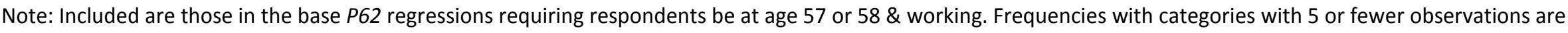
suppressed. Highlighted rows are discussed in the text as examples of the range of work expectations. 
2.6. Regressions of $P 62$ and $P 65$ on common covariates plus detailed occupation

Dependent variable:

$\operatorname{Pr}$ (work FT past 62) $\quad \operatorname{Pr}($ work FT past 65)

Wave

Good health or better

Has DB pension

Log total non-housing wealth

Log earnings

Educational category (reference category: <HS)

HS

Some college

College+

Married x Female (reference category: unmarried male)

Married $=0$ \# Female $=1$

Married $=1$ \# Female $=0$

Married=1 \# Female=1

Detailed occupation (reference category: financial managers)

Human resources, marketing, advertising, PR managers

Managers in education and related fields

Managers of medicine and health occupations

Managers of properties and real estate

Other managers

Accountants and auditors

Other financial specialists

Management analysts

Personnel, HR, training, and labor relations specialists

Purchasing managers, agents $\&$ buyers; bus. $\&$ promo agents

Inspectors and compliance officers

Management support occupations

Civil engineers

Electrical engineers

Industrial engineers

Mechanical engineers

Other engineers, architects, surveyors \& mapping scientists

Mathematical and Computer Scientists

Physical scientists

Life scientists

Physicians

Dentists

Other health and therapy occupations

Registered nurses

Pharmacist

Therapists

Dietitians, nutritionists and physicians assistants

Postsecondary teachers

Kindergarten and earlier school teachers

Primary school teachers

Secondary school teachers

Special education teachers

Pr(work FT past 62) Pr(work FT past 65)

$\begin{array}{cccc}\text { coef. } & \text { se } & \text { coef. } & \text { se } \\ 1.46 * * * & 0.23 & 1.59 * * * & 0.2 \\ 6.45 * * & 2.08 & 3.5 & 1.82 \\ -7.23 * * * & 1.37 & -8.15 * * * & 1.19 \\ -2.92 * * * & 0.42 & -2.88 * * * & 0.36 \\ 2.42 * * & 0.91 & 1.23 & 0.79 \\ & & & \\ -0.33 & 2.31 & 0.37 & 2.02 \\ 3.92 & 2.53 & 3.78 & 2.21 \\ 8.04 * * & 2.85 & 8.62 * * * & 2.49 \\ & & & \\ 5.74 * & 2.73 & 2.11 & 2.38 \\ 3.38 & 2.29 & -1.14 & 1.99 \\ -3.06 & 2.68 & -5.53 * & 2.33\end{array}$

$$
-2.7
$$

$-18.14$

$-17.16$

9.22

$-9.18$

$-7.97$

$-4.33$

8.41

$-4.53$

7.3

8.3

$-16.76^{*}$

7.2

10.82

$-13.89$

9.39

7.48

10.99

-9.16
$-17.20^{*}$

5.75

6.62

8.34

$-11.14$

9.61

$-0.37$

7.91

$-8.32$

12.64

$-0.35$

10.97

$-17.25$

10.61

$-17.18$

9.21

$-31.02 * *$

9.52

$-16.23^{*}$

8.26

$-15.69$

10.28

$-21.82^{*}$

8.92

$-16.66$

13.09

$-12.74$

11.36

$-8.37$

13.67

$-18.63$

11.86

4.71

11.89

$-3.74$

10.32

19.37

10.13

5.34

8.79

\subsection{7}

17.46

16.01

15.15

$-19.91 *$

10.63

$-4.96$

9.23

$-39.96 * *$

9.21

$-18.48 *$

7.99

\subsection{9}

15.14

$-29.12 *$

13.14

11.61

19.27

21.65

16.72

8.69

16.13

14.45

14

$-33.91 * *$

26.46

34.34

22.97

$-12.11$

12.24

$-25.10$

10.63

$-36.47$

7.86

$-3.78$

6.82

$-25.96 *$

21.93

$-30.56$

19.03

$-5.82$

12.23

$-21.72 *$

10.62

12.5

15.18

1.68

17.49

$-6.04$

7.02

$-30.33 *$

8.09

$-25.66 * * *$

12.25

$-26.78^{*}$

10.63

$-23.52^{* *}$

7.69

$-23.80 * * *$

6.69

$-26.64 *$

7.76

$-21.51 * *$

6.73

11.4 
2.6. Regressions of $P 62$ and $P 65$ on common covariates plus detailed occupation

Dependent variable:

$\operatorname{Pr}$ (work FT past 62) $\quad \operatorname{Pr}($ work FT past 65)

Teachers, nec

Vocational and educational counselors

coef.

Librarians, Archivists, and Curators

Psychologists

Other social scientists and urban planners

Social workers

Recreational workers

Clergy and religious workers

Lawyers and Judges

Writers, authors, technical writers

Designers

Musician or composer

Actors, directors, producers

Art makers: painters, sculptors, craft-artists, \& print-makers

Photographers

Art/entertainment performers and related

Editors and reporters

Athletes, sports instructors, officials and announcers

Clinical laboratory technologies \& techs, dental hygenists

Radiologic tech specialists

Licensed practical nurses

Health technologists and technicians, nec

Engineering, surveyor and mapping technicians

Drafters

Science technicians

Airplane pilots and navigators, air traffic controllers

Computer programmers, support specialists \& administrators

Technicians, nec

Supervisors and proprietors of sales jobs

Insurance sales occupations

Real estate sales occupations

Financial services sales occupations

Advertising and related sales jobs

Cashiers

Door-to-door sales, street sales, and news vendors

Other sales and sales related

Office supervisors

Computer and peripheral equipment operators

Secretaries, Stenographers, and Typists

Interviewers, enumerators, and surveyors

Transportation ticket and reservation agents

Information clerks, nec

Correspondence and order clerks

Human resources clerks, except payroll and timekeeping

Library assistants

File clerks

$-2.18$

$-7.78$

$-10.99$

$-12.39$

$-4.55$

$-6.85$

$-12.71$

6.91

12.88

5.83

8.73

$-1.4$

$-13.62$

$-8.94$

36.71

9.45

13.33

31.32

$-22.05$

$-27.97$

$-10.11$

$-8.49$

$-19.42$

10.09

$-8.54$

$-19.82$

$-17.49$

$-25.17^{*}$

$-6.64$

$-8.63$

$-6.23$

14.61

$-45.96 *$

$-22.60 *$

6.68

$-10.13$

$-13.54$

$-8.82$

$-13.03$

$-0.83$

$-32.95$

$-9.27$

$-4.22$

5.07

$-9.39$

$-14.35$ coef.

12.23

$-7.93$

se

11.08

$-19.04 *$

10.61

12.27

$-7.94$

10.65

13.63

$-16.15$

11.83

16.1

$-7.36$

13.98

8.93

$-10.24$

7.75

21.98

$-24.04$

19.08

10.03

2.35

8.82

12.24

16.13

10.62

26.48

$-13.81$

22.98

19.27

$-6.63$

15.15

37

8.23

32.11

36.95

$-21.67$

32.07

19.03

32.04

36.92

$-21.68$

19.03

$-14.2$

19.02

9.72

32.09

52.09

10.3

11.87

$-26.94 * *$

19.01

$-12.92$

9.12

10.51

$-17.68$

9.86

$-5.23$

8.95

10.31

$-12.1$

16.76

10.62

12.24

6.43

15.13

17.43

$-4.52$

8.42

9.59

$-18.86$

10.03

11.56

$-18.49$

6.45

$-2.87$

10.04

$-3.76$

12.43

5.35

13.13

22.21

19.04

21.95

$-31.45$

8.42

9.7

$-22.83 *$

16.72

19.26

14.07

6.32

6.62

7.63

$-10.93$

$-14.28 *$

10.09

$-17.16$

6.17

7.11

$-12.25^{*}$

15.16

19.03

$-13.41$

8.21

$-18.58 *$

15.16

19.08

12.45

$-20.7$

16.72 
2.6. Regressions of $P 62$ and $P 65$ on common covariates plus detailed occupation

Dependent variable:

Pr(work FT past 62) $\quad \operatorname{Pr}($ work FT past 65)

Records clerks

Bookkeepers and accounting and auditing clerks

Other financial records processing occupations

Duplicating, mail, and other office machine operators

Postal clerks, excluding mail carriers

Mail carriers for postal service

Mail clerks, outside of post office

Messengers

Dispatchers

Shipping and receiving clerks

Stock and inventory clerks

Weighers, measurers, checkers, meter readers

Material recording, sched, prod, plan, \& expediting clerks

Insurance adjusters, examiners, and investigators

Cust. service reps, investigators $\&$ adjusters, exc insurance

Eligibility clerks for government programs; social welfare

Bill and account collectors

General office clerks

Bank tellers

Data entry keyers

Teacher assistants

Other administrative support occupations

Supervisors of mechanics and repairers

Automobile mechanics

Bus, truck, and stationary engine mechanics

Aircraft mechanics

Auto body repairers

Heavy equipment and farm equipment mechanics

Industrial machinery repairers

Other machinery maintenance and repairers

Repairers of industrial electrical equipment

Repairers of data process. equip. or other office machines

Telecom and line installers and repairers

Heating, air conditioning, and refigeration mechanics

Other electronic or electrical equipment repairers

Precision makers, repairers \& smiths, mech \& elevator repair

Other mechanics and repairers

Supervisors of construction work

Masons, tilers, and carpet installers

Carpenters

Drywall installers

Electricians, electric power installers and repairers

Painters, construction and maintenance

Plumbers, pipe fitters, and steamfitters

Other construction trades

Production supervisors or foremen

coef.

$\begin{array}{llll}-7.22 & 21.96 & 8 & 19.05\end{array}$

$\begin{array}{llll}-12.77 & 7.74 & -11.5 & 6.72\end{array}$

$\begin{array}{llll}-1.99 & 10.05 & -4.17 & 8.72\end{array}$

$\begin{array}{llll}-31.91 * & 16.15 & -24.03 & 14.02\end{array}$

$\begin{array}{llll}2.16 & 11.93 & -13.85 & 10.36\end{array}$

$\begin{array}{llll}-27.02 * & 11.93 & -22.72 * & 10.35\end{array}$

$\begin{array}{llll}-17.77 & 17.48 & -32.25^{*} & 15.17\end{array}$

$\begin{array}{llll}-3.53 & 16.17 & 0.82 & 14.04\end{array}$

$\begin{array}{llll}-30.39 * & 11.93 & -27.39 * * & 10.36\end{array}$

$\begin{array}{llll}-38.69 * * * & 10.39 & -28.40 * * & 9.16\end{array}$

$\begin{array}{llll}-17.53 & 9.01 & -15.49 * & 7.82\end{array}$

$\begin{array}{llll}-9.74 & 17.49 & -18.88 & 15.18\end{array}$

$\begin{array}{llll}-27.22 * & 11.34 & -36.29 * * * & 10.09\end{array}$

$\begin{array}{llll}-8.89 & 12.25 & -12.34 & 10.63\end{array}$

$\begin{array}{llll}-15.28 & 9.36 & -8.46 & 8.13\end{array}$

$\begin{array}{llll}-9.52 & 14.32 & -5.08 & 12.43\end{array}$

$\begin{array}{llll}11.79 & 13.65 & 8.45 & 11.85\end{array}$

$\begin{array}{llll}-20.02 * & 9.91 & -10.73 & 8.6\end{array}$

$\begin{array}{llll}-15.79 & 11.36 & -23.18^{*} & 9.86\end{array}$

$\begin{array}{llll}-22.95 & 14.35 & -25.63 * & 12.45\end{array}$

$\begin{array}{llll}-22.22 * & 10.3 & -25.08 * * & 8.94\end{array}$

$\begin{array}{llll}-1.36 & 9.88 & -7.55 & 8.57\end{array}$

$\begin{array}{llll}-13.44 & 9.49 & -7.98 & 8.23\end{array}$

$\begin{array}{llll}10.19 & 15.22 & 7.66 & 13.21\end{array}$

$\begin{array}{llll}-8.23 & 14.4 & -18.09 & 12.5\end{array}$

$\begin{array}{llll}-10.74 & 21.96 & -14.55 & 19.06\end{array}$

$\begin{array}{llll}-3.68 & 37.03 & 18.41 & 32.13\end{array}$

$\begin{array}{llll}-19.62 & 16.19 & -34.42 * & 14.05\end{array}$

$\begin{array}{llll}-14.38 & 9.54 & -16.05 & 8.28\end{array}$

$\begin{array}{llll}17.58 & 17.49 & -6.29 & 15.17\end{array}$

$\begin{array}{llll}-15.82 & 21.95 & -6.43 & 19.04\end{array}$

$\begin{array}{llll}-3.46 & 26.54 & -15.88 & 23.03\end{array}$

$\begin{array}{llll}-25.25 * & 11.66 & -11.96 & 10.12\end{array}$

$\begin{array}{llll}-28.79 & 15.18 & -21.87 & 13.18\end{array}$

$\begin{array}{llll}-11.97 & 16.19 & -21.86 & 14.05\end{array}$

$\begin{array}{llll}-23.41 & 17.49 & -19.99 & 15.17\end{array}$

$\begin{array}{llll}-7.2 & 9.54 & -4.5 & 8.28\end{array}$

$\begin{array}{llll}-9.08 & 9 & -12.35 & 7.86\end{array}$

$\begin{array}{llll}-49.50 * & 22.04 & -25.97 & 19.13\end{array}$

$\begin{array}{llll}-27.24 * & 12.04 & -19.55 & 10.45\end{array}$

$\begin{array}{llll}-60.63 & 37.06 & -31.87 & 32.16\end{array}$

$\begin{array}{llll}-16.31 & 10.93 & -22.59 * & 9.48\end{array}$

$\begin{array}{llll}-10.16 & 13.18 & -12.46 & 11.44\end{array}$

$\begin{array}{llll}-21.04 & 11.14 & -20.12 * & 9.67\end{array}$

$\begin{array}{llll}-18.45 & 11.02 & -17.32 & 9.57\end{array}$

$\begin{array}{llll}-15.12 & 8.3 & -16.25^{*} & 7.23\end{array}$ 
2.6. Regressions of $P 62$ and $P 65$ on common covariates plus detailed occupation

Dependent variable:

$\operatorname{Pr}$ (work FT past 62) $\quad \operatorname{Pr}($ work FT past 65)

Precision metal working occupations

coef.

Precision woodworking occupations

Precision textile, apparel, and furnishings machine workers

Optical goods workers, dental lab \& med appliance tech

Other precision workers, assorted materials

Butchers and meat cutters

Bakers and batch food makers

Plant and system operators, adjusters and calibrators

Farm operators and managers

Farm occupations, except managerial

Gardeners and groundskeepers

Other agricultural occupations

Timber, logging, and forestry workers

Metal working and plastic working machine operators

Metal and plastic processing machine operators

Woodworking machine operators

Textile sewing machine operators

Laundry workers

Other textile, apparel, and furnishings machine operators

Packers, fillers, and wrappers

Painting machine operators

Slicing and cutting machine operators

Other machine operators, assorted materials

Welders, metal cutters, solderers

Assemblers and fabricators

Production inspectors, testers, samplers, and weighers

Supervisors of motor vehicle transportation

Truck, delivery, tractor drivers and parking lot attendants

Industrial truck and tractor operators

Bus drivers

Taxi cab drivers and chauffeurs

Rail transportation occupations

Water transportation occupations

Construction equipment operators

Crane, derrick, winch, and hoist operators

Misc material moving occupations

Construction helpers and laborers, surveyor helpers

Production helpers

Vehicle washers and equipment cleaners

Packers and packagers by hand

Other freight, stock, and material handlers

$-18.4$

se coef.

$-72.75^{*}$

36.98

$-21.47^{*}$

se

$-13.81$

36.98

$-49.45$

32.09

7.02

19.3

$-41.44 *$

16.75

$-1.38$

15.14

$-8.12$

13.13

$-17.44$

10.37

$-13.04$

9

4.68

14.41

$-14.74$

12.5

$-19.81$

19.35

3.82

16.8

9.11

11.14

$-19.54^{*}$

9.67

$-17.22$

21.93

10.67

19.03

$-16.04$

11.15

$-12.02$

9.67

$-24.22$

10.86

$-19.26^{*}$

9.43

22.36

19.36

19.11

16.8

$-25.87 *$

26.62

$-22.58$

23.1

32.71

10.73

$-18.72 *$

9.31

$-21.96$

23

$-8.53$

26.51

$-4.08$

16.76

$-28.14$

19.31

$-17.67$

13.25

$-30.93$

22

$-5.33$

19.09

13.05

22.01

$-39.95 *$

19.1

$-24.06$

17.48

0.9

14.04

$-24.19$

21.95

$-9.99$

19.05

$-4.49$

21.93

0.77

19.03

$-22.98 * *$

7.97

$-17.35 *$

6.92

$-20.19$

10.42

$-18.36 *$

9.19

$-20.51^{*}$

8.96

$-12.59$

7.78

$-24.26 * *$

9.39

$-23.71 * *$

8.15

$-6.23$

11.14

$-15.82$

9.67

$-14.31 \quad 7.65$

$-11.19$

6.65

$-22.32 *$

9.9

$-27.00 * *$

8.59

$-16.85$

9.95

$-11.04$

8.64

$-26.32$

14.37

$-19.97$

12.47

$-23.95$

15.2

$-17.37$

13.2

$-40.2$

36.99

$-33.97$

32.1

$-33.00 * *$

10.99

$-27.78 * *$

9.54

$-21.28$

22.11

$-15.41$

19.19

3.45

16.24

$-0.36$

14.09

$-34.81 * * \quad 10.61$

$-28.15^{* *}$

9.21

35.4

37.03

50.58

32.13

$-24.62$

17.53

$-29.77$

15.21

$-26.27$

15.23

$-12.44$

13.22

$-23.38^{* *}$

8.77

$-19.51^{*}$

7.62

$-18.6$

9.65

$-18.04^{*}$

8.38

Firefighting, prevention, and inspection

17.87

26.55

16.39

23.04

$-31.83 * * \quad 10.86$

$-18.86^{*}$

9.43

$-26.65^{*}$

13.17

$-30.00 * *$

11.43

Guards, watchmen, doorkeepers

$-24.53^{*}$

10.61

$-24.26 * *$

9.21 
2.6. Regressions of $P 62$ and $P 65$ on common covariates plus detailed occupation

Dependent variable:

$\operatorname{Pr}$ (work FT past 62) $\quad \operatorname{Pr}($ work FT past 65)

Other protective services

Private household occupations

\begin{tabular}{|c|c|c|c|}
\hline coef. & se & coef. & se \\
\hline-46.27 & 36.99 & -25.64 & 32.1 \\
\hline$-20.27^{*}$ & 9.5 & $-16.21^{*}$ & 8.25 \\
\hline$-52.95^{*}$ & 26.56 & -35.25 & 23.05 \\
\hline-15.81 & 14.41 & 3.75 & 12.51 \\
\hline-12.72 & 11.96 & -3.62 & 10.38 \\
\hline-17.18 & 10.1 & $-20.63^{*}$ & 8.77 \\
\hline-25.81 & 19.34 & -18.61 & 16.78 \\
\hline-18.36 & 19.43 & $-37.40 *$ & 16.86 \\
\hline-22.07 & 16.22 & $-28.89 *$ & 14.07 \\
\hline$-19.50 *$ & 7.85 & $-19.17 * *$ & 6.88 \\
\hline-16.75 & 11.66 & -1.91 & 10.12 \\
\hline-25.57 & 13.7 & $-32.12 * *$ & 11.89 \\
\hline$-25.01^{*}$ & 11.08 & $-27.43^{* *}$ & 9.62 \\
\hline$-21.78 * *$ & 8.24 & $-25.62 * * *$ & 7.18 \\
\hline-12.45 & 21.95 & 10.43 & 19.05 \\
\hline-34.71 & 19.3 & -25.65 & 16.75 \\
\hline$-23.86^{*}$ & 10.96 & -17.74 & 9.51 \\
\hline-10.92 & 9.58 & -7.58 & 8.32 \\
\hline-51.2 & 26.46 & -31.39 & 22.96 \\
\hline $55.99 * * *$ & 12.25 & $49.71^{* * *}$ & 10.66 \\
\hline \multicolumn{2}{|l|}{0.14} & \multicolumn{2}{|c|}{0.17} \\
\hline \multicolumn{2}{|l|}{0.09} & \multicolumn{2}{|c|}{0.12} \\
\hline \multicolumn{2}{|l|}{0.000} & \multicolumn{2}{|c|}{0.000} \\
\hline \multicolumn{2}{|l|}{3410} & \multicolumn{2}{|c|}{3395} \\
\hline
\end{tabular}

Bartenders

Waiter/waitress, food counter and fountain workers

Chefs, head cooks and food supervisors

Other cooks

Kitchen workers

Waiter's assistant

Misc food prep workers

Janitors

Other cleaning \& bldg service occupations, exc households

Dental assistants

Health aides, except nursing

Nursing aides, orderlies, and attendants

Barbers, hairdressers and cosmetologists

Recreation facility attendants

Child care workers

Other personal service occupations

Military

Constant

R-squared

Adjusted R-squared

F-test p-value

3410

3395

Note: Results from OLS regression with P62/P65 (probability of full-time work past age 62/65) as dependent variable. Base (excluded) categories are less than high school, unmarried males, and financial managers. Wave indicates HRS wave, $1=1992$ through $11=2012$. Significance levels denoted as $*$ for $p<0.05, * *$ for $p<0.01, * * *$ for $p<0.001$. 


\begin{tabular}{|c|c|c|c|c|}
\hline \multirow[b]{2}{*}{ Dependent variable: $\operatorname{Pr}($ work FT past 65 ) } & \multicolumn{2}{|c|}{ (1) } & \multicolumn{2}{|c|}{ (2) } \\
\hline & coef. & se & coef. & se \\
\hline Usual retirement age in this type of job (self-report) & $1.82^{* * *}$ & 0.24 & & \\
\hline Dummy for no usual retirement in job (based on self-report) & & & $6.54 * * *$ & 1.46 \\
\hline Wave & $1.61 * * *$ & 0.27 & $1.60 * * *$ & 0.24 \\
\hline Good health or better & $4.80^{*}$ & 2.42 & 3.78 & 2.06 \\
\hline Has DB pension & $-5.79 * * *$ & 1.56 & $-7.64 * * *$ & 1.37 \\
\hline Log total non-housing wealth & $-2.94 * * *$ & 0.48 & $-2.95 * * *$ & 0.4 \\
\hline Log earnings & 0.69 & 1.12 & 1.44 & 0.94 \\
\hline \multicolumn{5}{|l|}{ Educational category (reference category: $<\mathrm{HS}$ ) } \\
\hline HS & 2.89 & 2.82 & 0.73 & 2.41 \\
\hline Some college & 4.48 & 3.04 & 4.67 & 2.6 \\
\hline College+ & $7.50^{*}$ & 3.41 & $8.05^{* *}$ & 2.9 \\
\hline \multicolumn{5}{|l|}{ Married x Female (reference category: unmarried male) } \\
\hline Married=0 \# Female=1 & 1.87 & 3.09 & 2.46 & 2.68 \\
\hline Married $=1$ \# Female $=0$ & 2.2 & 2.56 & 0.31 & 2.24 \\
\hline Married=1 \# Female=1 & -3.12 & 3.01 & -3.42 & 2.64 \\
\hline \multicolumn{5}{|l|}{ Detailed occupation (reference category: financial managers) } \\
\hline Human resources, marketing, advertising, PR managers & -11.12 & 8.51 & -5.66 & 7.86 \\
\hline Managers in education and related fields & $-17.28^{*}$ & 8.54 & $-21.20 * *$ & 7.81 \\
\hline Managers of medicine and health occupations & -12.64 & 11.96 & -10.39 & 10.01 \\
\hline Managers of properties and real estate & 16.59 & 15.09 & 12.83 & 13.38 \\
\hline Other managers & -11.3 & 6.82 & -10.6 & 6.1 \\
\hline Accountants and auditors & $-21.53^{*}$ & 10.55 & -17.32 & 8.88 \\
\hline Other financial specialists & -12.26 & 9.42 & -1.53 & 8.45 \\
\hline Management analysts & -6 & 14.98 & -7.08 & 12.61 \\
\hline Personnel, HR, training, and labor relations specialists & $-30.39 * *$ & 11.51 & $-28.22 * *$ & 10.23 \\
\hline Purchasing managers, agents $\&$ buyers; bus. \& promo agents & -20.64 & 10.6 & $-20.21 *$ & 9.3 \\
\hline Inspectors and compliance officers & $-20.60^{*}$ & 9.98 & $-21.11 *$ & 9.29 \\
\hline Management support occupations & $-31.89 *$ & 14.99 & -15.65 & 12.61 \\
\hline Civil engineers & -22.24 & 16.47 & -23.68 & 14.18 \\
\hline Electrical engineers & -13.25 & 11.17 & -4.04 & 10.53 \\
\hline Industrial engineers & 4.7 & 9.95 & 9.01 & 9.63 \\
\hline Mechanical engineers & -4.67 & 18.64 & -0.13 & 19.22 \\
\hline Other engineers, architects, surveyors \& mapping scientists & -12.05 & 10.83 & -12.18 & 10.01 \\
\hline Mathematical and Computer Scientists & $-25.64 * *$ & 9.6 & $-23.46 * *$ & 8.65 \\
\hline Physical scientists & -24.47 & 13.19 & $-27.71 *$ & 13.34 \\
\hline Life scientists & & & 17.43 & 23.24 \\
\hline Physicians & 0.33 & 18.62 & 21.37 & 15.32 \\
\hline Dentists & 3.76 & 30.98 & 32.26 & 23.17 \\
\hline Other health and therapy occupations & $-29.24 *$ & 11.97 & $-28.17^{*}$ & 11.57 \\
\hline Registered nurses & -5.15 & 8.28 & -2.15 & 7.33 \\
\hline Pharmacist & -31.78 & 18.66 & -28.84 & 19.24 \\
\hline Therapists & -20.64 & 11.53 & -21.12 & 11.17 \\
\hline Dietitians, nutritionists and physicians assistants & 3.22 & 16.6 & 6.26 & 16.98 \\
\hline Postsecondary teachers & -7.1 & 8.47 & -3.34 & 7.59 \\
\hline Kindergarten and earlier school teachers & -15.21 & 12.02 & $-25.22 *$ & 11.19 \\
\hline Primary school teachers & $-19.47^{*}$ & 8.1 & $-23.61 * *$ & 7.26 \\
\hline
\end{tabular}




\begin{tabular}{|c|c|c|c|c|}
\hline \multirow[b]{2}{*}{ Dependent variable: $\operatorname{Pr}($ work FT past 65$)$} & \multicolumn{2}{|c|}{ (1) } & \multicolumn{2}{|c|}{ (2) } \\
\hline & coef. & se & coef. & se \\
\hline Secondary school teachers & $-15.97^{*}$ & 7.95 & $-21.98^{* *}$ & 7.29 \\
\hline Special education teachers & -23.32 & 15 & $-23.31^{*}$ & 11.61 \\
\hline Teachers, nec & -2.43 & 12.53 & -9.15 & 10.82 \\
\hline Vocational and educational counselors & -22.58 & 12.02 & -21.13 & 11.2 \\
\hline Librarians, Archivists, and Curators & -9.74 & 13.99 & -4.8 & 11.61 \\
\hline Psychologists & -14.46 & 13.12 & -14.05 & 12.6 \\
\hline Other social scientists and urban planners & -28.2 & 18.63 & -14 & 15.31 \\
\hline Social workers & $-19.42^{*}$ & 9.49 & -12.14 & 8.41 \\
\hline Recreational workers & $-69.10^{*}$ & 31.08 & -26.4 & 19.3 \\
\hline Clergy and religious workers & -12.44 & 10.43 & 2.46 & 9.49 \\
\hline Lawyers and Judges & 7.74 & 12.46 & 11.27 & 11.16 \\
\hline Writers, authors, technical writers & $-70.60 *$ & 31.6 & -17.18 & 23.2 \\
\hline Designers & & & -6.2 & 16.94 \\
\hline Musician or composer & 7.46 & 31.14 & 10.72 & 32.38 \\
\hline Actors, directors, producers & -24.15 & 31.06 & -19.44 & 32.33 \\
\hline Art makers: painters, sculptors, craft-artists, \& print-makers & -7.62 & 22.4 & 12.3 & 19.22 \\
\hline Photographers & -29.64 & 31.02 & -22.3 & 32.29 \\
\hline Art/entertainment performers and related & -29.62 & 31.01 & -17.9 & 19.24 \\
\hline Editors and reporters & 3.35 & 18.63 & 10.12 & 19.21 \\
\hline \multicolumn{5}{|l|}{ Athletes, sports instructors, officials and announcers } \\
\hline Clinical laboratory technologies \& techs, dental hygenists & $-25.33^{*}$ & 11.55 & $-23.43^{*}$ & 11.59 \\
\hline Radiologic tech specialists & -0.9 & 22.35 & -15.12 & 19.21 \\
\hline Licensed practical nurses & $-27.62 *$ & 12.07 & -18.46 & 10.6 \\
\hline Health technologists and technicians, nec & -11.4 & 11.7 & -7.29 & 10.62 \\
\hline Engineering, surveyor and mapping technicians & -11.4 & 10.66 & -9.32 & 10.05 \\
\hline Drafters & 5.61 & 18.73 & 9.19 & 19.28 \\
\hline Science technicians & -12.96 & 13.16 & -10.86 & 12.06 \\
\hline Airplane pilots and navigators, air traffic controllers & -16.25 & 15 & -17.94 & 15.32 \\
\hline Computer programmers, support specialists \& administrators & -15.81 & 9.89 & -11.12 & 8.86 \\
\hline Technicians, nec & $-25.03^{*}$ & 11.51 & -18.5 & 10.52 \\
\hline Supervisors and proprietors of sales jobs & -15.53 & 7.92 & -5.16 & 6.97 \\
\hline Insurance sales occupations & -10.56 & 13.14 & -5.66 & 10.82 \\
\hline Real estate sales occupations & 4.89 & 18.73 & 2.19 & 12.65 \\
\hline Financial services sales occupations & $38.25^{*}$ & 18.62 & $43.30 *$ & 16.88 \\
\hline Advertising and related sales jobs & -38.88 & 22.39 & -32 & 23.2 \\
\hline Cashiers & -18.52 & 10.5 & $-21.89 *$ & 9.14 \\
\hline Door-to-door sales, street sales, and news vendors & & & 8.04 & 16.95 \\
\hline Other sales and sales related & $-21.88 * *$ & 7.9 & $-16.73^{*}$ & 6.77 \\
\hline Office supervisors & -15.03 & 7.82 & $-14.46 *$ & 7.04 \\
\hline Computer and peripheral equipment operators & $-29.94 *$ & 13.99 & -23.66 & 13.36 \\
\hline Secretaries, Stenographers, and Typists & $-15.70^{*}$ & 7.56 & $-14.25^{*}$ & 6.65 \\
\hline Interviewers, enumerators, and surveyors & -2.5 & 22.44 & 2.85 & 15.38 \\
\hline Transportation ticket and reservation agents & -3.17 & 22.47 & -0.2 & 23.24 \\
\hline Information clerks, nec & -14.43 & 10.97 & -16.39 & 9.22 \\
\hline Correspondence and order clerks & -12.54 & 16.5 & -16.38 & 15.37 \\
\hline Human resources clerks, except payroll and timekeeping & -22.66 & 31.3 & -28.19 & 23.31 \\
\hline
\end{tabular}




\begin{tabular}{|c|c|c|c|c|}
\hline \multirow[b]{2}{*}{ Dependent variable: $\operatorname{Pr}($ work FT past 65 ) } & \multicolumn{2}{|c|}{ (1) } & \multicolumn{2}{|c|}{ (2) } \\
\hline & coef. & se & coef. & se \\
\hline Library assistants & 3.09 & 14 & 11.15 & 14.22 \\
\hline File clerks & 2.22 & 18.72 & 5.67 & 19.26 \\
\hline Records clerks & -16.54 & 31.05 & 28.89 & 23.22 \\
\hline Bookkeepers and accounting and auditing clerks & $-17.03^{*}$ & 8.32 & -12.55 & 7.35 \\
\hline Other financial records processing occupations & -2.11 & 10.64 & -4.85 & 9.68 \\
\hline Duplicating, mail, and other office machine operators & -23.2 & 18.73 & -23.38 & 16.94 \\
\hline Postal clerks, excluding mail carriers & -11 & 11.59 & -12.86 & 10.88 \\
\hline Mail carriers for postal service & -22.04 & 12.14 & $-24.13^{*}$ & 11.63 \\
\hline Mail clerks, outside of post office & -49.33 & 31.18 & $-37.01 *$ & 16.94 \\
\hline Messengers & -5.02 & 16.54 & -1.1 & 14.25 \\
\hline Dispatchers & $-36.27 * *$ & 12.55 & $-28.51 *$ & 11.63 \\
\hline Shipping and receiving clerks & $-35.24 * *$ & 11 & $-31.44 * *$ & 10.12 \\
\hline Stock and inventory clerks & -11.6 & 9.91 & -10.78 & 8.89 \\
\hline Weighers, measurers, checkers, meter readers & -8.77 & 18.81 & -16.79 & 16.96 \\
\hline Material recording, sched., prod, plan, \& expediting clerks & $-36.87 * *$ & 12.04 & $-38.20 * * *$ & 10.89 \\
\hline Insurance adjusters, examiners, and investigators & -20.05 & 12.02 & -17.61 & 11.61 \\
\hline Cust. service reps, investigators $\&$ adjusters, exc. insurance & -8.97 & 10.03 & -12.09 & 9.07 \\
\hline Eligibility clerks for government programs; social welfare & 1.9 & 18.69 & -3.14 & 13.33 \\
\hline Bill and account collectors & -2.72 & 15.03 & 11.62 & 12.62 \\
\hline General office clerks & -19.97 & 10.45 & -14.1 & 9.88 \\
\hline Bank tellers & -22.38 & 12.11 & $-24.74 *$ & 11.26 \\
\hline Data entry keyers & $-32.93 *$ & 16.55 & $-28.08 *$ & 14.23 \\
\hline Teacher assistants & $-21.24 *$ & 10.66 & $-25.13 * *$ & 9.48 \\
\hline Other administrative support occupations & -8.89 & 10.71 & -7.41 & 9.69 \\
\hline Supervisors of mechanics and repairers & -15.96 & 10.01 & -10.63 & 9.08 \\
\hline Automobile mechanics & 9.56 & 16.65 & 1.89 & 14.28 \\
\hline Bus, truck, and stationary engine mechanics & -22.8 & 13.28 & -19.08 & 13.42 \\
\hline Aircraft mechanics & -18.34 & 18.71 & -14.02 & 19.27 \\
\hline \multicolumn{5}{|l|}{ Auto body repairers } \\
\hline Heavy equipment and farm equipment mechanics & -35.71 & 31.18 & $-34.23^{*}$ & 16.95 \\
\hline Industrial machinery repairers & -18.55 & 9.94 & -15.19 & 9.15 \\
\hline Other machinery maintenance and repairers & -3.73 & 16.54 & -7.01 & 15.38 \\
\hline Repairers of industrial electrical equipment & -20.15 & 22.43 & -8.72 & 19.25 \\
\hline Repairers of data process. equip. or other office machines & & & -39.03 & 32.31 \\
\hline Telecom and line installers and repairers & -15.96 & 11.66 & -11.52 & 10.91 \\
\hline Heating, air conditioning, and refrigeration mechanics & -24.88 & 15.11 & -22.46 & 13.39 \\
\hline Other electronic or electrical equipment repairers & $-29.67^{*}$ & 15.11 & -26.34 & 15.4 \\
\hline Precision makers, repairers \& smiths, mech. \& elevator repair & -23.92 & 16.54 & -21.43 & 15.38 \\
\hline Other mechanics and repairers & -9.96 & 10.3 & 0.49 & 9.57 \\
\hline Supervisors of construction work & $-19.02 *$ & 9.3 & -14.82 & 8.55 \\
\hline Masons, tilers, and carpet installers & -31.95 & 22.56 & -28.01 & 23.31 \\
\hline Carpenters & $-24.46^{*}$ & 12.18 & -19.32 & 11 \\
\hline Drywall installers & -32.56 & 31.23 & -30.73 & 32.45 \\
\hline Electricians, electric power installers and repairers & $-29.38 * *$ & 10.46 & $-23.43^{*}$ & 9.72 \\
\hline Painters, construction and maintenance & -25.9 & 15.09 & $-28.85^{*}$ & 13.38 \\
\hline Plumbers, pipe fitters, and steamfitters & $-24.46 *$ & 11.67 & $-23.64 *$ & 10.61 \\
\hline
\end{tabular}




\begin{tabular}{|c|c|c|c|c|}
\hline \multirow[b]{2}{*}{ Dependent variable: $\operatorname{Pr}($ work FT past 65$)$} & \multicolumn{2}{|c|}{ (1) } & \multicolumn{2}{|c|}{ (2) } \\
\hline & coef. & se & coef. & se \\
\hline Other construction trades & -21.17 & 12.22 & -21.2 & 11.33 \\
\hline Production supervisors or foremen & $-23.74 * *$ & 8.37 & $-20.32 * *$ & 7.79 \\
\hline Precision metal working occupations & $-29.94 * *$ & 10.73 & $-21.77^{*}$ & 9.73 \\
\hline Precision woodworking occupations & -42.44 & 31.17 & -47.48 & 32.38 \\
\hline Precision textile, apparel, and furnishings machine workers & -58.84 & 31.05 & $-48.03 *$ & 19.29 \\
\hline Optical goods workers, dental lab \& med appliance tech & -8.1 & 16.61 & -8.13 & 14.24 \\
\hline Other precision workers, assorted materials & -15.82 & 10.72 & -11.85 & 10.13 \\
\hline Butchers and meat cutters & -26.46 & 14.09 & -25.96 & 13.43 \\
\hline Bakers and batch food makers & -23.2 & 18.82 & 2.39 & 17.03 \\
\hline Plant and system operators, adjusters and calibrators & -18.9 & 11.3 & -19.07 & 10.63 \\
\hline Farm operators and managers & -2.21 & 31.04 & 6.96 & 19.24 \\
\hline Farm occupations, except managerial & 11.77 & 15.29 & -2.42 & 11.85 \\
\hline Gardeners and groundskeepers & -3.09 & 16.83 & -13.9 & 10.81 \\
\hline Other agricultural occupations & 17.59 & 22.54 & 23.76 & 23.29 \\
\hline Timber, logging, and forestry workers & -34.58 & 31.1 & -26.13 & 32.35 \\
\hline Metal working and plastic working machine operators & $-24.88^{*}$ & 10.76 & $-21.88^{*}$ & 10.13 \\
\hline Metal and plastic processing machine operators & -35.56 & 31.02 & -25.48 & 23.22 \\
\hline Woodworking machine operators & & & -9.1 & 17.01 \\
\hline Textile sewing machine operators & -11.07 & 18.85 & -8.73 & 19.36 \\
\hline Laundry workers & -48.71 & 31.1 & -9.5 & 19.33 \\
\hline Other textile, apparel, and furnishings machine operators & -36.88 & 31 & -32.7 & 32.28 \\
\hline Packers, fillers, and wrappers & 13.55 & 31.1 & 14.23 & 23.17 \\
\hline Painting machine operators & -0.06 & 22.42 & 4.99 & 23.21 \\
\hline Slicing and cutting machine operators & -15.2 & 22.46 & -0.19 & 19.23 \\
\hline Other machine operators, assorted materials & $-23.23 * *$ & 8.52 & -14.31 & 7.82 \\
\hline Welders, metal cutters, solderers & -18.8 & 10.31 & -16.34 & 9.95 \\
\hline Assemblers and fabricators & -15.03 & 9.28 & -13.42 & 8.45 \\
\hline Production inspectors, testers, samplers, and weighers & $-32.25 * *$ & 10.21 & $-28.27 * *$ & 9.53 \\
\hline Supervisors of motor vehicle transportation & -15.16 & 11.33 & -14.85 & 10.12 \\
\hline Truck, delivery, tractor drivers and parking lot attendants & $-18.30^{*}$ & 8.23 & -12.52 & 7.27 \\
\hline Industrial truck and tractor operators & $-28.30 * *$ & 10.17 & $-26.50 * *$ & 9.19 \\
\hline Bus drivers & -3.43 & 12.07 & -13.15 & 9.56 \\
\hline Taxi cab drivers and chauffeurs & -29.87 & 22.46 & -24.1 & 12.71 \\
\hline Rail transportation occupations & -24.51 & 16.62 & -27.47 & 16.98 \\
\hline \multicolumn{5}{|l|}{ Water transportation occupations } \\
\hline Construction equipment operators & $-33.15 * *$ & 12.15 & $-26.42^{*}$ & 10.98 \\
\hline Crane, derrick, winch, and hoist operators & 13.88 & 31.2 & -9.95 & 23.33 \\
\hline Misc material moving occupations & 7.57 & 16.62 & 15.53 & 17 \\
\hline Construction helpers and laborers, surveyor helpers & $-28.97^{*}$ & 11.34 & $-26.94 * *$ & 10.4 \\
\hline Production helpers & & & 46.34 & 32.43 \\
\hline Vehicle washers and equipment cleaners & -23.96 & 18.76 & $-31.49 *$ & 15.43 \\
\hline Packers and packagers by hand & 28.98 & 31.07 & -20.89 & 19.29 \\
\hline Other freight, stock, and material handlers & $-24.53^{*}$ & 9.55 & $-21.54 *$ & 8.47 \\
\hline Supervisors in protective services & $-20.33^{*}$ & 9.9 & $-20.05^{*}$ & 9.2 \\
\hline Firefighting, prevention, and inspection & -32.53 & 31.03 & -28.02 & 32.3 \\
\hline Police, detectives, and private investigators & -16.01 & 10.65 & -17.29 & 10.05 \\
\hline
\end{tabular}


(1)

Dependent variable: $\operatorname{Pr}($ work FT past 65)

Other law enforcement: sheriffs, bailiffs, correc inst officers

Guards, watchmen, doorkeepers

Other protective services

Private household occupations

Bartenders

Waiter/waitress, food counter and fountain workers

Chefs, head cooks and food supervisors

Other cooks

Kitchen workers

Waiter's assistant

Misc food prep workers

Janitors

Other cleaning \& bldg service occupations, exc households

Dental assistants

Health aides, except nursing

Nursing aides, orderlies, and attendants

Barbers, hairdressers and cosmetologists

Recreation facility attendants

Child care workers

Other personal service occupations

Military

Constant

R-squared

Adjusted R-squared

F-test $p$-value

Observations

$$
\text { coef. }
$$

$-35.31^{*}$

$-29.95$

$-15.51$

$-21.67$

$-8.73$

$-23.89$

$-38.01$

$-23.67$

$-45.38$

$-24.77 * *$

$-16.79$

$-30.49 *$

$-34.87^{*}$

$-30.77^{* * *}$

9.69

$-62.87 * *$

$-12.34$

3.94

$-13.48$

$-62.06 * *$

0.22

0.13

0.000

1929

Note: Significance levels denoted as $*$ for $p<0.05, * *$ for $p<0.01, * * *$ for $p<0.001$
(2)

se coef.

15.22

$-32.77 * *$

15.28

$-33.66 * *$

11.66

11

\section{1}

$-18.79 *$

8.98

$-40.82$

23.3

18.73

$-7.03$

14.28

13.24

$-5.57$

11.27

12.68

$-23.37^{*}$

10.39

22.46

$-29.33$

19.31

22.92

$-39.74 *$

17.12

31.08

$-33.61 *$

14.32

8.48

$-19.32 * *$

7.43

12.58

$-0.05$

10.93

15.05

$-33.67 *$

13.36

13.95

$-27.97 *$

11.21

9.08

$-30.18 * * *$

8

29.78

23.22

22.46

$-51.66 * *$

19.28

14.12

$-24.77^{*}$

10.41

12.1

$-6.87$

9.55

22.52

$-29.89$

23.17

21.33

45.72***

12.32

0.18

0.11

0.000

2700 
Table 3.1. Occupation by last occupation observed at age 63 or later, for respondents over age 66 in 2010

10 Most common occupations

\begin{tabular}{|c|c|c|c|}
\hline Occupation & Title & $\%$ No early retirement & Observations* \\
\hline 6 & Other managers & $57 \%$ & 159 \\
\hline 31 & Primary school teachers & $49 \%$ & 69 \\
\hline 62 & Supervisors and proprietors of sales jobs & $63 \%$ & 56 \\
\hline 69 & Other sales and sales related & $81 \%$ & 108 \\
\hline 72 & Secretaries, Stenographers, and Typists & $66 \%$ & 82 \\
\hline 81 & Bookkeepers and accounting and auditing clerks & $67 \%$ & 64 \\
\hline 155 & Truck, delivery, tractor drivers and parking lot attendants & $66 \%$ & 91 \\
\hline 173 & Guards, watchmen, doorkeepers & $82 \%$ & 50 \\
\hline 183 & Janitors & $67 \%$ & 125 \\
\hline 187 & Nursing aides, orderlies, and attendants & $68 \%$ & 78 \\
\hline \multicolumn{4}{|c|}{10 occupations with highest rates of last occupation observed at age 63 or later } \\
\hline Occupation & Title & $\%$ No early retirement & Observations* \\
\hline 24 & Other health and therapy occupations & $100 \%$ & $<10$ \\
\hline 42 & Lawyers and Judges & $100 \%$ & $<10$ \\
\hline 43 & Writers, authors, technical writers & $100 \%$ & $<10$ \\
\hline 49 & Art/entertainment performers and related & $100 \%$ & $<10$ \\
\hline 51 & Athletes, sports instructors, officials and announcers & $100 \%$ & $<10$ \\
\hline 109 & Other machinery maintenance and repairers & $100 \%$ & $<10$ \\
\hline 158 & Taxi cab drivers and chauffeurs & $96 \%$ & 28 \\
\hline 41 & Clergy and religious workers & $94 \%$ & 18 \\
\hline 87 & Messengers & $92 \%$ & 13 \\
\hline 9 & Management analysts & $91 \%$ & 11 \\
\hline 135 & Farm operators and managers & $90 \%$ & 20 \\
\hline
\end{tabular}

10 occupations with lowest rates of last occupation observed at age 63 or later

\begin{tabular}{|c|c|c|c|}
\hline Occupation & Title & $\%$ No early retirement & Observations* \\
\hline 3 & Managers in education and related fields & $44 \%$ & 18 \\
\hline 2 & Human resources, marketing, advertising, public relation managers & $44 \%$ & 16 \\
\hline 89 & Shipping and receiving clerks & $42 \%$ & 12 \\
\hline 11 & Purchasing managers, agents and buyers; business and promotion agents & $39 \%$ & 18 \\
\hline 54 & Licensed practical nurses & $38 \%$ & 13 \\
\hline 108 & Industrial machinery repairers & $37 \%$ & 19 \\
\hline 127 & Precision metal working occupations & $36 \%$ & 22 \\
\hline 144 & Textile sewing machine operators & $35 \%$ & 23 \\
\hline 126 & Production supervisors or foremen & $29 \%$ & 28 \\
\hline 150 & Other machine operators, assorted materials & $28 \%$ & 47 \\
\hline
\end{tabular}

* Number of observations includes "Yes," "No" and missing values for whether last occupation was observed at age 63 or later. Additionally, numbers of observations that are less than 10 have been masked to "<10." 
Table 3.2. Occupation by last occupation observed at age 66 or later for respondents over age 66 in 2010

10 Most common occupations

\begin{tabular}{|c|c|c|c|}
\hline Occupation & Title & $\%$ No early retirement & Observations* \\
\hline 6 & Other managers & $39 \%$ & 159 \\
\hline 31 & Primary school teachers & $33 \%$ & 69 \\
\hline 62 & Supervisors and proprietors of sales jobs & $43 \%$ & 56 \\
\hline 69 & Other sales and sales related & $67 \%$ & 108 \\
\hline 72 & Secretaries, Stenographers, and Typists & $48 \%$ & 82 \\
\hline 81 & Bookkeepers and accounting and auditing clerks & $48 \%$ & 64 \\
\hline 155 & Truck, delivery, tractor drivers and parking lot attendants & $54 \%$ & 91 \\
\hline 173 & Guards, watchmen, doorkeepers & $70 \%$ & 50 \\
\hline 183 & Janitors & $44 \%$ & 125 \\
\hline 187 & Nursing aides, orderlies, and attendants & $54 \%$ & 78 \\
\hline
\end{tabular}

\begin{tabular}{|c|c|c|c|}
\hline Occupation & Title & $\%$ No early retirement & Observations* \\
\hline 42 & Lawyers and Judges & $100 \%$ & $<10$ \\
\hline 87 & Messengers & $92 \%$ & 13 \\
\hline 158 & Taxi cab drivers and chauffeurs & $89 \%$ & 28 \\
\hline 174 & Other protective services & $89 \%$ & $<10$ \\
\hline 43 & Writers, authors, technical writers & $88 \%$ & $<10$ \\
\hline 45 & Musician or composer & $88 \%$ & $<10$ \\
\hline 51 & Athletes, sports instructors, officials and announcers & $86 \%$ & $<10$ \\
\hline 73 & Interviewers, enumerators, and surveyors & $83 \%$ & $<10$ \\
\hline 129 & Precision textile, apparel, and furnishings machine workers & $83 \%$ & $<10$ \\
\hline
\end{tabular}

10 occupations with lowest rates of last occupation observed at age 66 or later (excludes most common occupations)

\begin{tabular}{|c|c|c|c|}
\hline Occupation & Title & $\%$ No early retirement & Observations* \\
\hline 25 & Registered nurses & $36 \%$ & 42 \\
\hline 168 & Other freight, stock, and material handlers & $35 \%$ & 43 \\
\hline 19 & Mathematical and Computer Scientists & $33 \%$ & 21 \\
\hline 10 & Personnel, $\mathrm{HR}$, training, and labor relations specialists & $33 \%$ & 15 \\
\hline 127 & Precision metal working occupations & $32 \%$ & 22 \\
\hline 108 & Industrial machinery repairers & $32 \%$ & 19 \\
\hline 144 & Textile sewing machine operators & $30 \%$ & 23 \\
\hline 152 & Assemblers and fabricators & $24 \%$ & 37 \\
\hline 126 & Production supervisors or foremen & $18 \%$ & 28 \\
\hline 150 & Other machine operators, assorted materials & $15 \%$ & 47 \\
\hline
\end{tabular}

* Number of observations includes "Yes," "No" and missing values for whether last occupation was observed at age 63 or later. Additionally, numbers of observations that are less than 10 have been masked to "<10." 
Table 3.3. Regressions of early retirement and late retirement on occupation

\begin{tabular}{|c|c|c|c|c|c|}
\hline \multirow[b]{2}{*}{ Variable } & & \multicolumn{2}{|c|}{ Early retirement } & \multicolumn{2}{|c|}{ Late retirement } \\
\hline & & coef. & se & coef. & se \\
\hline Occupation & Title & & & & \\
\hline 1 & Financial Managers (excluded category) & \multicolumn{2}{|c|}{--} & \multicolumn{2}{|c|}{--} \\
\hline 5 & Managers of properties and real estate & -0.08 & 0.15 & $0.26 *$ & 0.15 \\
\hline 9 & Management analysts & -0.19 & 0.17 & $0.34 *$ & 0.18 \\
\hline 11 & $\begin{array}{l}\text { Purchasing managers, agents and buyers; business } \\
\text { and promotion agents }\end{array}$ & $0.30 * *$ & 0.15 & -0.24 & 0.16 \\
\hline 29 & Postsecondary teachers & -0.1 & 0.12 & $0.25^{* *}$ & 0.13 \\
\hline 31 & Primary school teachers & $0.22 *$ & 0.11 & -0.14 & 0.12 \\
\hline 39 & Social workers & -0.10 & 0.15 & $0.27^{*}$ & 0.16 \\
\hline 41 & Clergy and religious workers & -0.23 & 0.15 & $0.36 * *$ & 0.15 \\
\hline 42 & Lawyers and Judges & -0.29 & 0.23 & $0.52 * *$ & 0.24 \\
\hline 43 & Writers, authors, technical writers & -0.29 & 0.19 & $0.40 * *$ & 0.20 \\
\hline 44 & Designers & -0.16 & 0.19 & $0.40 * *$ & 0.20 \\
\hline 45 & Musician or composer & -0.16 & 0.19 & $0.40 * *$ & 0.20 \\
\hline 51 & $\begin{array}{l}\text { Athletes, sports instructors, officials and } \\
\text { announcers }\end{array}$ & -0.29 & 0.20 & $0.38^{*}$ & 0.21 \\
\hline 54 & Licensed practical nurses & $0.33^{* *}$ & 0.16 & -0.25 & 0.17 \\
\hline 64 & Real estate sales occupations & -0.09 & 0.15 & $0.32 * *$ & 0.16 \\
\hline 69 & Other sales and sales related & -0.11 & 0.11 & $0.20 *$ & 0.11 \\
\hline 87 & Messengers & -0.21 & 0.16 & $0.45^{* * *}$ & 0.17 \\
\hline 97 & General office clerks & -0.15 & 0.14 & $0.25^{*}$ & 0.15 \\
\hline 100 & Teacher assistants & -0.15 & 0.13 & $0.25^{*}$ & 0.14 \\
\hline 108 & Industrial machinery repairers & $0.28 *$ & 0.15 & -0.10 & 0.16 \\
\hline 126 & Production supervisors or foremen & $0.42 * * *$ & 0.13 & $-0.29 * *$ & 0.14 \\
\hline 127 & Precision metal working occupations & $0.31 * *$ & 0.14 & -0.13 & 0.15 \\
\hline 131 & Other precision workers, assorted materials & $0.24^{*}$ & 0.15 & $-0.37 * *$ & 0.15 \\
\hline 135 & Farm operators and managers & -0.19 & 0.14 & $0.37 * *$ & 0.15 \\
\hline 144 & Textile sewing machine operators & $0.33 * *$ & 0.14 & -0.14 & 0.15 \\
\hline 150 & Other machine operators, assorted materials & $0.43^{* * *}$ & 0.12 & $-0.32 * *$ & 0.13 \\
\hline 157 & Bus drivers & -0.15 & 0.13 & $0.25^{*}$ & 0.14 \\
\hline 158 & Taxi cab drivers and chauffeurs & $-0.25^{*}$ & 0.13 & $0.42 * * *$ & 0.14 \\
\hline 168 & Other freight, stock, and material handlers & $0.21 *$ & 0.12 & -0.10 & 0.13 \\
\hline 173 & Guards, watchmen, doorkeepers & -0.11 & 0.12 & $0.22 *$ & 0.12 \\
\hline 174 & Other protective services & -0.17 & 0.18 & $0.41 * *$ & 0.19 \\
\hline Constant & & $0.29 * * *$ & 0.10 & $0.48 * * *$ & 0.10 \\
\hline \multicolumn{2}{|l|}{ R-squared } & \multicolumn{2}{|c|}{0.13} & \multicolumn{2}{|c|}{0.15} \\
\hline \multicolumn{2}{|c|}{ Adjusted R-squared } & \multicolumn{2}{|c|}{0.07} & \multicolumn{2}{|c|}{0.09} \\
\hline \multicolumn{2}{|l|}{ Observations } & \multicolumn{2}{|c|}{2842} & \multicolumn{2}{|c|}{2842} \\
\hline
\end{tabular}

Linear probability models (OLS) with early or late retirement variables (0/1) as dependent variables and occupation dummies as regressors. All data from 2010. Includes respondents who were 51-61, working full-time, and not selfemployed at their baseline interview, and over age 66 in 2010. Early retirement equals 1 if the last observed occupation was before the age of 63 (those over 66 and still having a listed occupation in 2010 were coded as 0 ). Late retirement equals 1 if the last recorded occupation was at age 66 or later, or if the respondent was over 66 and still had a listed occupation in 2010. Excluded occupation is Financial Managers. Only occupations which were statistically significant in one of the two regressions are included. Significance levels denoted as * for $p<0.1, * *$ for $\mathrm{p}<0.05, * * *$ for $\mathrm{p}<0.01$. 
Table 3.4. Summary statistics for job characteristic variables and analyses

Mean Min Max 25th\% Median 75th\% St. Dev. Obs.

\begin{tabular}{|c|c|c|c|c|c|c|c|c|c|c|}
\hline & Early retirement & Last occ observed before age 63 ? $(\mathrm{Yes}=1, \mathrm{No}=0)$ & 0.38 & & & 0 & 0 & 1 & 0.49 & 3781 \\
\hline & Late retirement & Last occ observed at age $66+?(\mathrm{Yes}=1, \mathrm{No}=0)$ & 0.45 & & & 0 & 0 & 1 & 0.50 & 3781 \\
\hline Job cha & acteristics & & & & & & & & & \\
\hline Source & Variable & Description & Mean & Min & Max & 25th\% & Median & 75th\% & St. Dev. & Obs. \\
\hline HRS & More difficult (jdiff) & $\begin{array}{l}\text { Job requires doing more difficult things than } \\
\text { before (1-4, strongly agree to strongly disagree) }\end{array}$ & 2.59 & & & 2 & 3 & 3 & 0.80 & 3456 \\
\hline HRS & Lots of stress (jstres) & $\begin{array}{l}\text { Job involves a lot of stress (1-4, strongly agree to } \\
\text { strongly disagree) }\end{array}$ & 2.45 & & & 2 & 3 & 3 & 0.82 & 3658 \\
\hline HRS & Physical effort (jphys) & $\begin{array}{l}\text { Job requires physical effort (1-4, all/almost all the } \\
\text { time to none/almost none) }\end{array}$ & 2.81 & & & 2 & 3 & 4 & 1.12 & 3642 \\
\hline HRS & $\begin{array}{l}\text { Could reduce hours } \\
\text { (credh) }\end{array}$ & $\begin{array}{l}\text { Could reduce work hours if wanted to (Yes=1, } \\
\mathrm{No}=0 \text { ) }\end{array}$ & 0.36 & & & 0 & 0 & 1 & 0.48 & 3295 \\
\hline O*Net & Activity 4 & Analyzing data or information $(0-1)$ & 0.48 & 0.16 & 0.86 & 0.39 & 0.46 & 0.59 & 0.15 & 3780 \\
\hline O*Net & Activity 5 & Making decisions and solving problems $(0-1)$ & 0.62 & 0.37 & 0.90 & 0.54 & 0.61 & 0.71 & 0.13 & 3780 \\
\hline O*Net & Activity 9 & Controlling machines and processes $(0-1)$ & 0.38 & 0.04 & 0.83 & 0.23 & 0.33 & 0.51 & 0.19 & 3780 \\
\hline O*Net & Activity 11 & Interacting with computers $(0-1)$ & 0.48 & 0.08 & 0.91 & 0.29 & 0.51 & 0.65 & 0.21 & 3780 \\
\hline O*Net & Activity 13 & $\begin{array}{l}\text { Repairing and maintaining electronic equipment } \\
(0-1)\end{array}$ & 0.22 & 0.00 & 0.81 & 0.13 & 0.19 & 0.27 & 0.12 & 3780 \\
\hline O*Net & Activity 14 & Documenting/recording information (0 - 1) & 0.53 & 0.15 & 0.82 & 0.45 & 0.53 & 0.64 & 0.15 & 3780 \\
\hline O*Net & Activity 16 & Assisting and caring for others $(0-1)$ & 0.46 & 0.21 & 0.94 & 0.35 & 0.42 & 0.56 & 0.15 & 3780 \\
\hline O*Net & Activity 17 & $\begin{array}{l}\text { Performing for or working directly with the public } \\
(0-1)\end{array}$ & 0.49 & 0.03 & 0.89 & 0.37 & 0.50 & 0.62 & 0.18 & 3780 \\
\hline O*Net & Activity 18 & Coaching and developing others $(0-1)$ & 0.47 & 0.16 & 0.79 & 0.35 & 0.44 & 0.58 & 0.15 & 3780 \\
\hline O*Net & Ability 3 & Mathematical reasoning $(0-1)$ & 0.34 & 0.00 & 0.73 & 0.27 & 0.34 & 0.43 & 0.13 & 3780 \\
\hline O*Net & Ability 4 & Arm-hand steadiness $(0-1)$ & 0.35 & 0.00 & 0.68 & 0.19 & 0.38 & 0.47 & 0.17 & 3780 \\
\hline
\end{tabular}


Table 3.5. Regressions of early retirement and late retirement on HRS job characteristics and detailed occupation

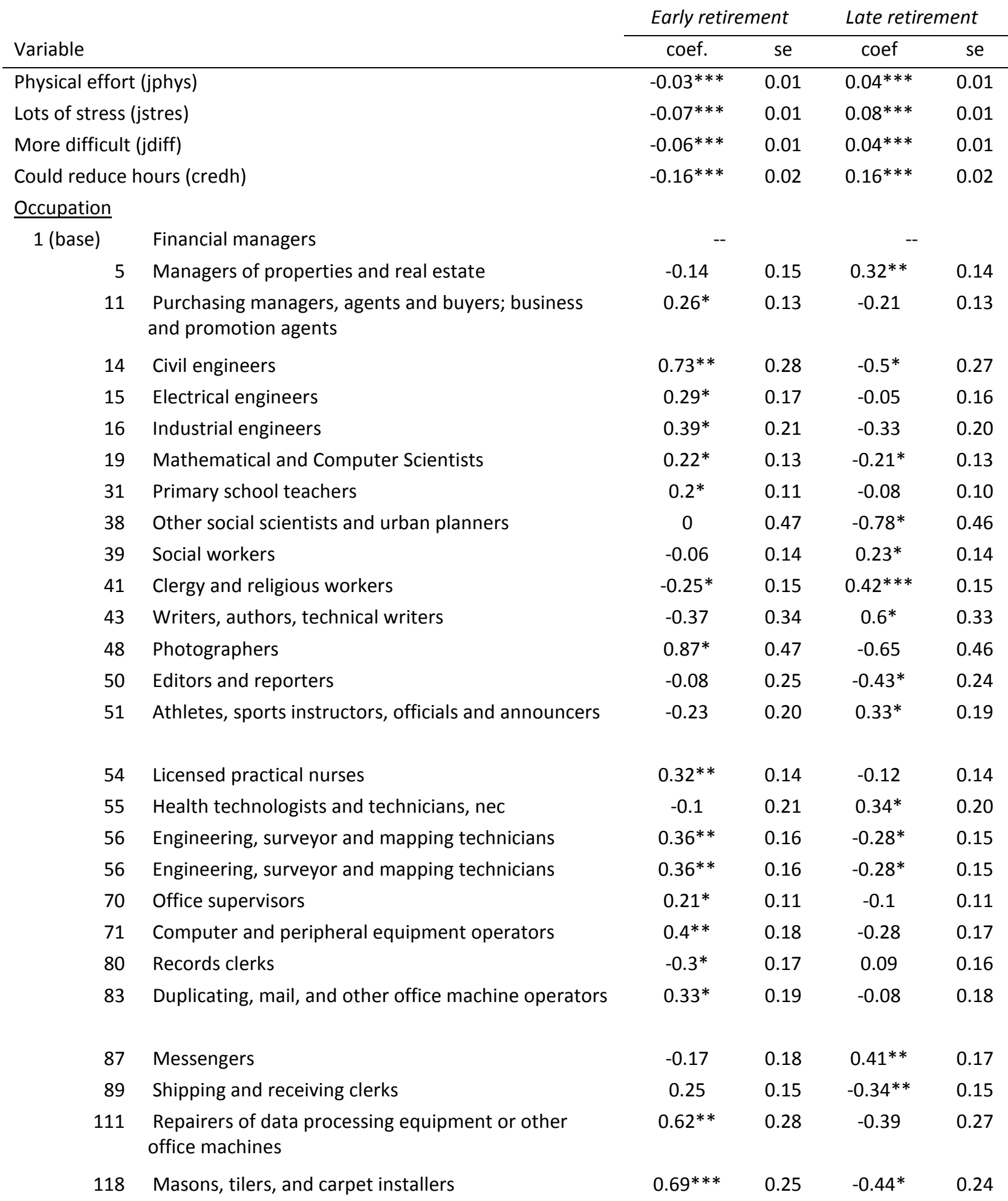




\begin{tabular}{|c|c|c|c|c|c|}
\hline \multirow{2}{*}{\multicolumn{2}{|c|}{ Table 3.5 (cont) }} & \multicolumn{2}{|c|}{ Early retirement } & \multicolumn{2}{|c|}{ Late retirement } \\
\hline & & \multirow{2}{*}{$\frac{\text { coef. }}{0.53^{* * *}}$} & \multirow{2}{*}{$\begin{array}{c}\text { se } \\
0.16\end{array}$} & \multirow{2}{*}{$\frac{\text { coef }}{-0.36^{* *}}$} & \multirow{2}{*}{$\frac{\text { se }}{0.16}$} \\
\hline 123 & Plumbers, pipe fitters, and steamfitters & & & & \\
\hline 125 & Extractive occupations & $0.82^{*}$ & 0.47 & -0.57 & 0.46 \\
\hline 126 & Production supervisors or foremen & $0.27 * *$ & 0.12 & -0.15 & 0.12 \\
\hline 127 & Precision metal working occupations & $0.35 * * *$ & 0.13 & -0.19 & 0.13 \\
\hline 131 & Other precision workers, assorted materials & $0.23 *$ & 0.13 & $-0.27^{* *}$ & 0.13 \\
\hline 138 & Other agricultural occupations & $0.56 * *$ & 0.28 & -0.3 & 0.27 \\
\hline 139 & Timber, logging, and forestry workers & $0.65^{*}$ & 0.34 & -0.39 & 0.33 \\
\hline 143 & Woodworking machine operators & $0.49 * *$ & 0.21 & $-0.41 * *$ & 0.20 \\
\hline 143 & Woodworking machine operators & $0.49 * *$ & 0.21 & $-0.41 * *$ & 0.20 \\
\hline 144 & Textile sewing machine operators & $0.36^{* * *}$ & 0.13 & -0.2 & 0.13 \\
\hline 146 & $\begin{array}{l}\text { Other textile, apparel, and furnishings machine } \\
\text { operators }\end{array}$ & 0.32 & 0.20 & $-0.36^{*}$ & 0.19 \\
\hline 147 & Packers, fillers, and wrappers & 0.2 & 0.20 & $-0.37^{*}$ & 0.19 \\
\hline 150 & Other machine operators, assorted materials & $0.31 * * *$ & 0.11 & $-0.28 * * *$ & 0.11 \\
\hline 153 & $\begin{array}{l}\text { Production inspectors, testers, samplers, and } \\
\text { weighers }\end{array}$ & $0.25^{* *}$ & 0.12 & $-0.22 *$ & 0.12 \\
\hline 157 & Bus drivers & -0.17 & 0.12 & $0.29 * *$ & 0.11 \\
\hline 158 & Taxi cab drivers and chauffeurs & -0.1 & 0.12 & $0.28 * *$ & 0.12 \\
\hline 160 & Water transportation occupations & -0.57 & 0.47 & $0.81^{*}$ & 0.46 \\
\hline 161 & Construction equipment operators & $0.35^{* *}$ & 0.15 & -0.17 & 0.15 \\
\hline 163 & Misc material moving occupations & $0.48 * *$ & 0.20 & $-0.38^{* *}$ & 0.19 \\
\hline 165 & Production helpers & $0.44^{*}$ & 0.25 & -0.2 & 0.24 \\
\hline 167 & Packers and packagers by hand & $0.34 * *$ & 0.17 & -0.09 & 0.16 \\
\hline 174 & Other protective services & -0.27 & 0.20 & $0.51^{* * *}$ & 0.19 \\
\hline Constant & & $0.78^{* * *}$ & 0.1 & -0.05 & 0.1 \\
\hline R-squared & & 0.1 & & 0.21 & \\
\hline Adjusted R-sq & ared & 0.1 & & 0.16 & \\
\hline Observations & & 305 & & 305 & \\
\hline
\end{tabular}

Regressions are linear probability models. Dependent variables are early retirement or late retirement indicators. Same sample restrictions as in regressions of retirement on occupation, except these use last occupation observed and its characteristics, max one observation per respondent, for those who are observed past age 66. Early retirement is equal to 1 if last observed occupation in HRS data was at age 62 or earlier, and zero otherwise. Late retirement is equal to 1 if last observed occupation in HRS data was at age 66 or later, and zero otherwise. Excluded occupation is Financial Managers. Only occupations which were statistically significant in one of the two regressions are reported in table. Significance levels denoted as * for $p<0.1, * *$ for $p<0.05, * * *$ for $p<0.01$. 
Table 3.6. Regressions of early retirement on job characteristics

\begin{tabular}{|c|c|c|c|c|c|c|}
\hline \multirow{2}{*}{$\begin{array}{l}\text { Covariate source } \\
\text { Variable }\end{array}$} & \multicolumn{2}{|c|}{ HRS only } & \multicolumn{2}{|c|}{ O*Net only } & \multicolumn{2}{|c|}{ Both } \\
\hline & coef & se & coef & se & coef & se \\
\hline Physical effort (jphys) & $-0.04 * * *$ & 0.01 & & & $-0.03 * * *$ & 0.01 \\
\hline Lots of stress (jstres) & $-0.08 * * *$ & 0.01 & & & $-0.08 * * *$ & 0.01 \\
\hline More difficult (jdiff) & $-0.06 * * *$ & 0.01 & & & $-0.06^{* * *}$ & 0.01 \\
\hline Could reduce hours (credh) & $-0.19 * * *$ & 0.02 & & & $-0.17 * * *$ & 0.02 \\
\hline Activity 4 & & & $-0.34 * *$ & 0.17 & -0.29 & 0.19 \\
\hline Activity 5 & & & -0.04 & 0.15 & 0.09 & 0.17 \\
\hline Activity 9 & & & $0.42 * * *$ & 0.10 & $0.32 * * *$ & 0.11 \\
\hline Activity 11 & & & $0.3^{* * *}$ & 0.08 & $0.21^{* *}$ & 0.09 \\
\hline Activity 13 & & & 0.03 & 0.11 & 0.01 & 0.12 \\
\hline Activity 14 & & & 0.05 & 0.12 & -0.04 & 0.13 \\
\hline Activity 16 & & & 0 & 0.09 & -0.1 & 0.10 \\
\hline Activity 17 & & & $-0.37 * * *$ & 0.05 & $-0.25 * * *$ & 0.06 \\
\hline Activity 18 & & & $0.22^{* *}$ & 0.09 & 0.15 & 0.10 \\
\hline Ability 3 & & & 0.12 & 0.10 & $0.21 *$ & 0.11 \\
\hline Ability 4 & & & -0.15 & 0.12 & -0.05 & 0.13 \\
\hline Constant & $0.95 * * *$ & 0.04 & $0.32 * * *$ & 0.06 & $0.82^{* * *}$ & 0.08 \\
\hline R-squared & 0.10 & & $0 . c$ & & 0.1 & \\
\hline Adjusted R-squared & 0.10 & & 0.0 & & 0.1 & \\
\hline Observations & 3051 & & 37 & & 30 & \\
\hline \multicolumn{7}{|c|}{$\begin{array}{l}\text { Regressions are linear probability models. Dependent variable is early retirement indicator. Same sample } \\
\text { restrictions as in regressions of retirement on occupation, except these use characteristics of last occupation } \\
\text { observed, max one observation per respondent, for those who are observed past age } 66 \text {. Early retirement is } \\
\text { equal to } 1 \text { if last observed occupation in HRS data was at age } 62 \text { or earlier, and zero otherwise. Significance } \\
\text { levels denoted as * for } p<0.1,{ }^{* *} \text { for } p<0.05, * * * \text { for } p<0.01 \text {. }\end{array}$} \\
\hline
\end{tabular}


Table 3.7. Regressions of late retirement on job characteristics

\begin{tabular}{|c|c|c|c|c|c|c|}
\hline \multirow{2}{*}{$\begin{array}{l}\text { Covariate source: } \\
\text { Variable }\end{array}$} & \multicolumn{2}{|c|}{ HRS only } & \multicolumn{2}{|c|}{ O*Net only } & \multicolumn{2}{|c|}{ Both } \\
\hline & coef & se & coef & se & coef & se \\
\hline Physical effort (jphys) & $0.04^{* * *}$ & 0.01 & & & $0.04^{* * *}$ & 0.01 \\
\hline Lots of stress (jstres) & $0.09^{* * *}$ & 0.01 & & & $0.09 * * *$ & 0.01 \\
\hline More difficult (jdiff) & $0.06 * * *$ & 0.01 & & & $0.05^{* * *}$ & 0.01 \\
\hline Could reduce hours (credh) & $0.2^{* * *}$ & 0.02 & & & $0.17^{* * *}$ & 0.02 \\
\hline Activity 4 & & & $0.29 *$ & 0.17 & 0.27 & 0.18 \\
\hline Activity 5 & & & 0.07 & 0.16 & -0.19 & 0.16 \\
\hline Activity 9 & & & $-0.46^{* * *}$ & 0.10 & $-0.33^{* * *}$ & 0.10 \\
\hline Activity 11 & & & $-0.33 * * *$ & 0.08 & $-0.22^{* *}$ & 0.09 \\
\hline Activity 13 & & & -0.03 & 0.11 & 0.02 & 0.12 \\
\hline Activity 14 & & & -0.11 & 0.12 & -0.02 & 0.12 \\
\hline Activity 16 & & & 0.05 & 0.09 & $0.17^{*}$ & 0.10 \\
\hline Activity 17 & & & $0.39 * * *$ & 0.05 & $0.3^{* * *}$ & 0.06 \\
\hline Activity 18 & & & $-0.18 *$ & 0.09 & -0.04 & 0.10 \\
\hline Ability 3 & & & -0.08 & 0.11 & -0.17 & 0.11 \\
\hline Ability 4 & & & 0.17 & 0.12 & 0.09 & 0.12 \\
\hline Constant & $-0.15 * * *$ & 0.04 & $0.48^{* * *}$ & 0.07 & -0.07 & 0.08 \\
\hline R-squared & \multicolumn{2}{|c|}{0.11} & \multicolumn{2}{|c|}{0.05} & \multicolumn{2}{|c|}{0.15} \\
\hline Adjusted R-squared & \multicolumn{2}{|c|}{0.11} & \multicolumn{2}{|c|}{0.05} & \multicolumn{2}{|c|}{0.14} \\
\hline Observations & \multicolumn{2}{|c|}{3051} & \multicolumn{2}{|c|}{3780} & \multicolumn{2}{|c|}{3051} \\
\hline
\end{tabular}

Regressions are linear probability models. Dependent variable is late retirement indicator. Same sample restrictions as in regressions of retirement on occupation, except these use characteristics of last occupation observed, max one observation per respondent, for those who are observed past age 66. Late retirement is equal to 1 if last observed occupation in HRS data was at age 66 or later, and zero otherwise. Significance levels denoted as * for $\mathrm{p}<0.1, * *$ for $\mathrm{p}<0.05, * * *$ for $\mathrm{p}<0.01$. 